\title{
Crater gradation in Gusev crater and Meridiani Planum, Mars
}

\author{
J. A. Grant, ${ }^{1}$ R. E. Arvidson, ${ }^{2}$ L. S. Crumpler, ${ }^{3}$ M. P. Golombek, ${ }^{4}$ B. Hahn, ${ }^{5}$ \\ A. F. C. Haldemann, ${ }^{4}$ R. Li, ${ }^{6}$ L. A. Soderblom, ${ }^{7}$ S. W. Squyres, ${ }^{8}$ S. P. Wright, ${ }^{9}$ \\ and W. A. Watters ${ }^{10}$ \\ Received 19 April 2005; revised 21 June 2005; accepted 27 June 2005; published 6 January 2006.
}

[1] The Mars Exploration Rovers investigated numerous craters in Gusev crater and Meridiani Planum during the first $\sim 400$ sols of their missions. Craters vary in size and preservation state but are mostly due to secondary impacts at Gusev and primary impacts at Meridiani. Craters at both locations are modified primarily by eolian erosion and infilling and lack evidence for modification by aqueous processes. Effects of gradation on crater form are dependent on size, local lithology, slopes, and availability of mobile sediments. At Gusev, impacts into basaltic rubble create shallow craters and ejecta composed of resistant rocks. Ejecta initially experience eolian stripping, which becomes weathering-limited as lags develop on ejecta surfaces and sediments are trapped within craters. Subsequent eolian gradation depends on the slow production of fines by weathering and impacts and is accompanied by minor mass wasting. At Meridiani the sulfate-rich bedrock is more susceptible to eolian erosion, and exposed crater rims, walls, and ejecta are eroded, while lower interiors and low-relief surfaces are increasingly infilled and buried by mostly basaltic sediments. Eolian processes outpace early mass wasting, often produce meters of erosion, and mantle some surfaces. Some small craters were likely completely eroded/buried. Craters $>100 \mathrm{~m}$ in diameter on the Hesperian-aged floor of Gusev are generally more pristine than on the Amazonian-aged Meridiani plains. This conclusion contradicts interpretations from orbital views, which do not readily distinguish crater gradation state at Meridiani and reveal apparently subdued crater forms at Gusev that may suggest more gradation than has occurred.

Citation: Grant, J. A., et al. (2006), Crater gradation in Gusev crater and Meridiani Planum, Mars, J. Geophys. Res., 111, E02S08, doi:10.1029/2005JE002465.

\section{Introduction}

[2] The Mars Exploration Rovers (MER) Spirit and Opportunity have been providing unprecedented views of Martian impact craters since landing on the floor of Gusev crater $\left(14.5692^{\circ} \mathrm{S}, 175.4729^{\circ} \mathrm{E}\right)$ and in Meridiani Planum

\footnotetext{
${ }^{1}$ Center for Earth and Planetary Studies, National Air and Space Museum, Smithsonian Institution, Washington, DC, USA.

${ }^{2}$ Department of Earth and Planetary Sciences, Washington University, St. Louis, Missouri, USA.

${ }^{3}$ New Mexico Museum of Natural History and Science, Albuquerque, New Mexico, USA.

${ }^{4}$ Jet Propulsion Laboratory, California Institute of Technology, Pasadena, California, USA.

${ }^{5}$ Department of Geosciences, State University of New York, Stony Brook, New York, USA.

${ }^{6}$ Department of Civil and Environmental Engineering and Geodetic Science, Ohio State University, Columbus, Ohio, USA

${ }^{7}$ U.S. Geological Survey, Flagstaff, Arizona, USA. USA.

${ }^{8}$ Department of Astronomy, Cornell University, Ithaca, New York,

${ }^{9}$ Department of Geological Sciences, Arizona State University, Tempe, Arizona, USA.

${ }^{10}$ Department of Earth, Atmospheric, and Planetary Sciences, Massachusetts Institute of Technology, Cambridge, Massachusetts, USA.

Copyright 2006 by the American Geophysical Union. 0148-0227/06/2005JE002465
}

$\left(1.9483^{\circ} \mathrm{S}, 354.4742^{\circ} \mathrm{E}\right)$, respectively, in January 2004 [e.g., Grant et al., 2004; Squyres et al., 2004a, 2004b; Arvidson et al., 2006; Golombek et al., 2006]. Craters explored through the first $\sim 400$ sols at both landing sites range in size from less than $1 \mathrm{~m}$ to well over $100 \mathrm{~m}$ in diameter, are in varying stages of preservation, and all are simple bowl-shaped structures whose pristine form can be predicted to reasonable accuracy [e.g., Melosh, 1989; Garvin et al., 2000].

[3] The pristine form of craters on the Earth and Mars is modified by the action of geomorphic processes that contribute both degradational (erosional) and aggradational (infilling) signatures, collectively referred to here as gradation. Using gradational morphology at simple, unglaciated craters on Earth as a template [Grant, 1999; Grant and Schultz, 1993; Grant et al., 1997], comparison between the Mars craters' current form and their expected pristine appearance can yield clues regarding the amount of gradation that has occurred. More specifically, such comparisons can help define what role, if any, water has played in gradation of the Martian craters.

[4] A summary of morphology associated with pristine simple craters and typical gradational signatures evolved at terrestrial craters follows. Subsequent sections focus on gradation of craters explored in Gusev crater and Meridiani 


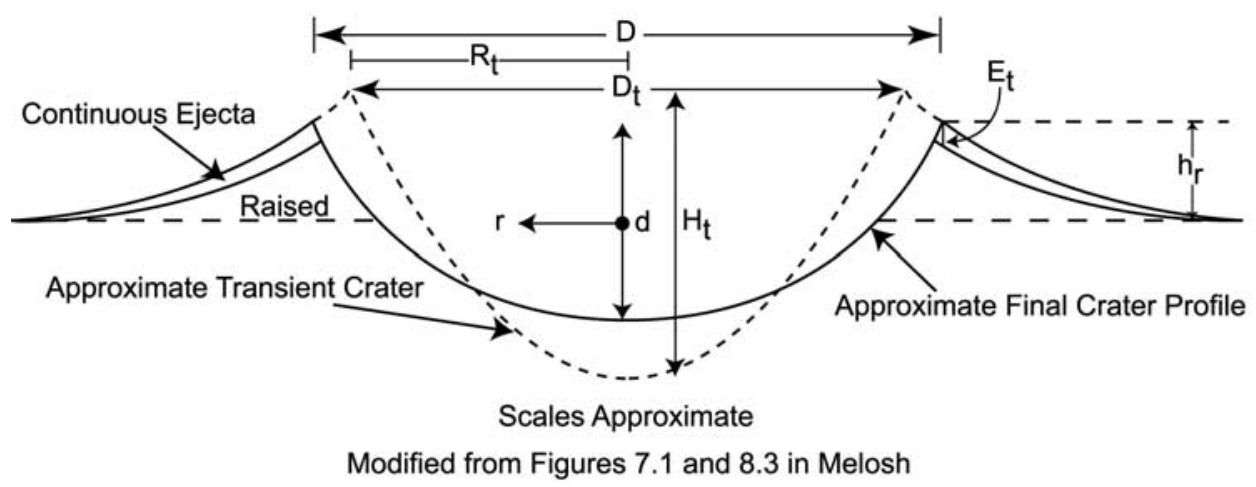

Figure 1. Idealized cross section through a simple impact crater. Parameters discussed in equations (1)(5) are labeled.

Planum, respectively, that are considerably smaller but likely similar in pristine form to the terrestrial craters [Melosh, 1989]. This paper is part of a series that reports results from the first several hundred sols of Spirit and Opportunity operations as detailed by Arvidson et al. [2006] and S. W. Squyres et al. (Overview of the Opportunity Mars Exploration Rover mission to Meridiani Planum: Landing site to the etched terrain, manuscript in preparation, 2006).

\section{Overview of Pristine Simple Crater Morphology}

[5] The pristine morphology of impact craters and their associated ejecta deposits on the Earth and planets has been the subject of numerous studies [e.g., Quaide and Oberbeck, 1968; Gault et al., 1968; Gault, 1970; McGetchin et al., 1973; Moore et al., 1974; Shoemaker and Kieffer, 1974; Pike, 1977a, 1977b; Roddy, 1978; Schultz and Gault, 1979; Melosh, 1989; Schultz, 1992]. In general, pristine craters less than several kilometers in diameter possess a simple bowl shape, a well-defined raised rim, and a variety of morphologic characteristics (Figure 1) that are predictable in most respects [e.g., Melosh, 1989]. For example, individual morphologic parameters can vary from crater to crater [e.g., Garvin et al., 2000], and the origin of some attributes remains controversial (e.g., origin of rampart ejecta facies around craters on Mars [Melosh, 1989; Barlow, 2005]). However, relationships between dimensions of the late-stage transient cavity versus those of the final crater, the characteristic raised rim height with respect to crater diameter, and other parameters are well understood [McGetchin et al., 1973; Melosh, 1989; Garvin et al., 2000, 2003]. From Melosh [1989], transient crater diameter $D_{t}$ and depth $H_{t}$ for impacts into solid materials can be related to the final diameter $D$, depth $d$, and rim height $h_{r}$ by

$$
\begin{gathered}
D_{t}=0.84 D, \\
H_{t} / D_{t}=1 / 2.7, \\
h_{r}=0.035 D .
\end{gathered}
$$

Near-rim thickness of the ejecta deposit $E_{t}$ in meters can be related to the transient crater radius $R_{t}$ and radial distance $r$ from the crater center, where $r>R_{t}[$ McGetchin et al., 1973]:

$$
E_{t}=0.14 R_{t}^{0.74}\left(r / R_{t}\right)^{-3.0}
$$

Finally, estimates of the range in size $l_{b}$ (in meters) of the largest near-rim rocks ejected during crater formation can also be obtained [Moore, 1971; Melosh, 1989] using

$$
l_{b} \sim(k) D^{2 / 3},
$$

where the coefficient $k$ has a range of $0.1-0.3$.

[6] For simple craters excavated by primary impactors arriving from space and traveling at speeds greater than a few kilometers per second, the final, pristine depth-todiameter ratio $d / D$ is typically $\sim 0.2$ [Pike, 1977a; Pike and Wilhelms, 1978] but may approach $\sim 0.3$ to $\sim 0.5$ for some craters on Mars that are $\sim 100 \mathrm{~m}$ and $\sim 10 \mathrm{~m}$ in diameter, respectively [Garvin et al., 2003]. For secondary craters on Mars, which formed as slower-moving material ejected during the primary impact event reimpacts the surface some distance away, rims and planform can be somewhat less well-defined than for primary craters, and $d / D$ is typically $\sim 0.10$ [Pike, 1980; Melosh, 1989; Hurst et al., 2004; McEwen et al., 2005]. Although less predictable, impacts into layered targets can produce benches on crater walls, thereby influencing pristine crater morphology [Quaide and Oberbeck, 1968].

\section{Overview of Characteristic Crater Gradational Form}

[7] Field work and remote observations of unglaciated, simple craters on the Earth that formed in relatively homogenous and/or flat-lying target rocks define morphology that can help constrain their gradational history. As summarized by Grant [1999], Grant and Schultz [1993], and Grant et al. [1997], intercrater comparisons of morphology permit the definition of a sequence of expected morphologic form associated with increasing modification by fluvial, mass-wasting, or eolian processes (Figures 2 and 3), that often is largely independent of climate.

[8] Relatively pristine craters, such as the $1.2 \mathrm{~km}$ diameter Meteor crater in Arizona, are characterized by walls sloping 30-49 (Figures 2 and 3). During early modifica- 

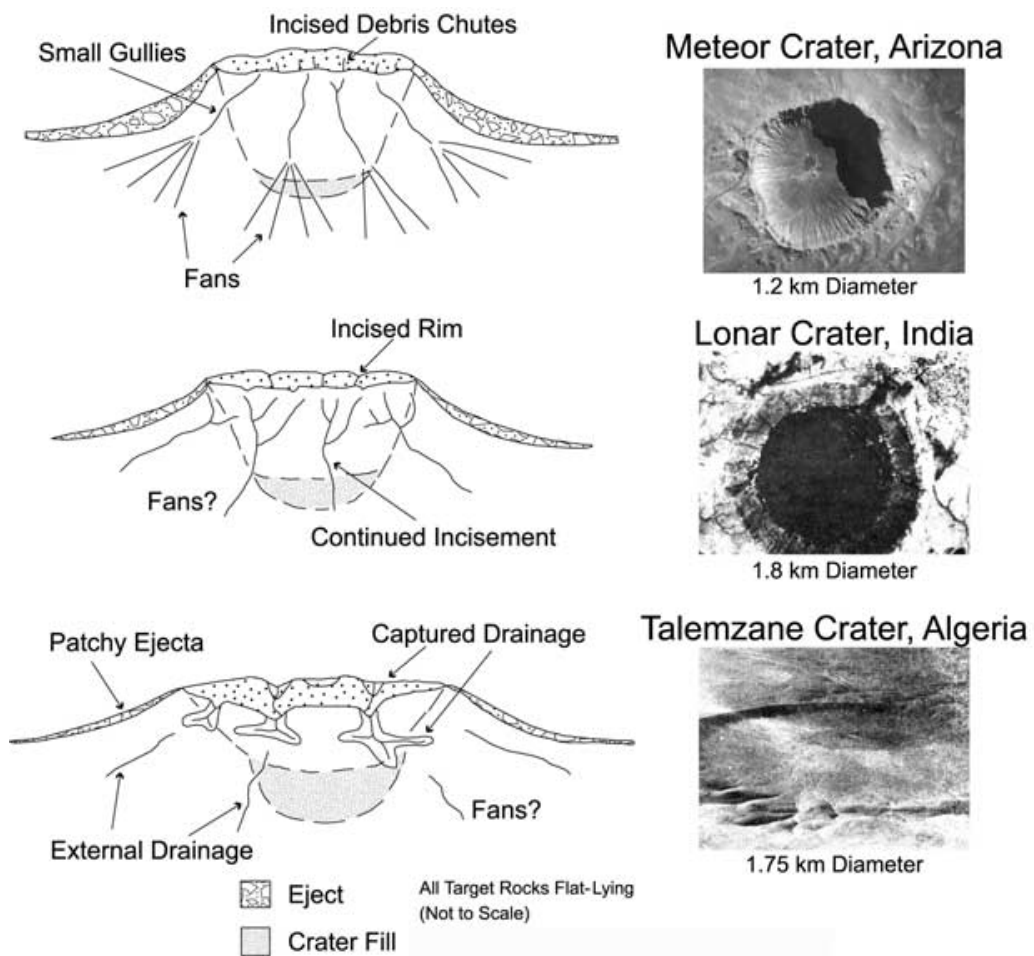

Figure 2. Idealized perspective views of first-order morphology associated with increasing gradation around simple terrestrial craters formed in flat-lying or homogeneous target rocks. Features evolved on both the exterior (near-field, no pattern) and interior (far-field, stippled patterns) are indicated. Fluvial signatures evolve quickly to large scales that persist at more advanced stages of gradation, even in arid settings. After Grant [1999].

tion, mass wasting dominates and causes back wasting of the interior walls, as rubble is redistributed downslope in debris chutes. Runoff along the wall incises the debris chutes, thereby contributing to an initially high apparent drainage density $\left(13.7 \mathrm{~km} / \mathrm{km}^{2}\right.$ in Meteor crater). Outside the crater, erosion downwastes the rim crest, but the lowersloping distal ejecta are characterized by high infiltration capacities [Grant and Schultz, 1993] that impede runoff and limit incision. Exposed ejecta also experiences early deflation and colluvial modification that quickly create lags of coarse fragments, further impeding erosion by runoff. Comparison between incipient interior and exterior drainages reveals a smaller apparent scale and density $(3.4 \mathrm{~km} /$ $\mathrm{km}^{2}$ ) outside the crater.

[9] As gradation progresses, crater walls remain steep (e.g., locally exceeding $35-36^{\circ}$ ) and are completely stripped (Figure 2). Incipient drainages erode headward and incise the rim as exemplified by the $1.8-\mathrm{km}$-diameter Lonar crater in India (Figure 2). Fluvial gradation overtakes mass wasting and accounts for continued back wasting of the wall and redistribution of talus as fans farther out on the crater floor. At the same time, the cross section and density of the drainages along the wall may decrease (e.g., to $4.6 \mathrm{~km} / \mathrm{km}^{2}$ ) as the debris chutes in which they originated are destroyed. Drainages outside the crater continue to expand and produce moderate densities (e.g., $4.3 \mathrm{~km} / \mathrm{km}^{2}$ ), but gradation by all processes beyond the relatively steep near-rim is limited by the lag-armored properties of the ejecta deposit.
[10] More advanced gradation is typified by the $1.75-\mathrm{km}$ diameter Talemzane crater in Algeria and the $2.5-\mathrm{km}$ diameter Roter Kamm crater in Namibia (Figures 2 and 3). Wall drainages continue to erode headward, breach the rim, capture headward portions of exterior basins, and result in increasing drainage density (e.g., $6.5 \mathrm{~km} / \mathrm{km}^{2}$ at Talemzane). Mostly fluvial redistribution of material onto the crater floor creates coalescing fans (Figure 2), and back wasting of walls due mostly to fluvial activity results in crater enlargement of $\sim 10 \%$ that is accompanied by a reduction in wall slopes (e.g., $22-35^{\circ}$ at Talemzane). Erosion outside the crater is slowed by exposure of bedrock

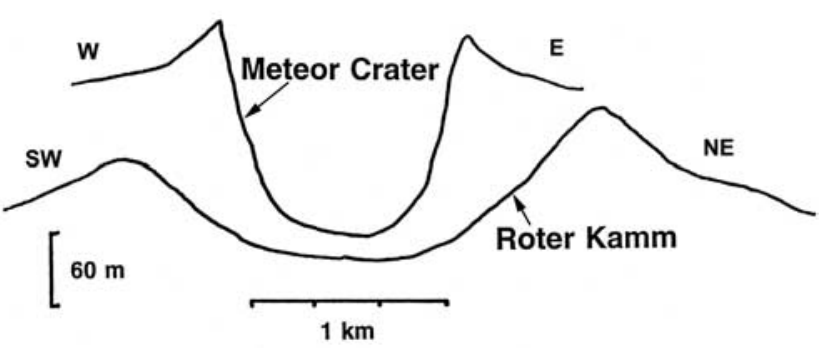

Figure 3. Comparison of topographic profiles across the relatively pristine Meteor crater in Arizona and the more degraded Roter Kamm crater in Namibia. Slightly modified from Grant et al. [1997, Figure 2]. 


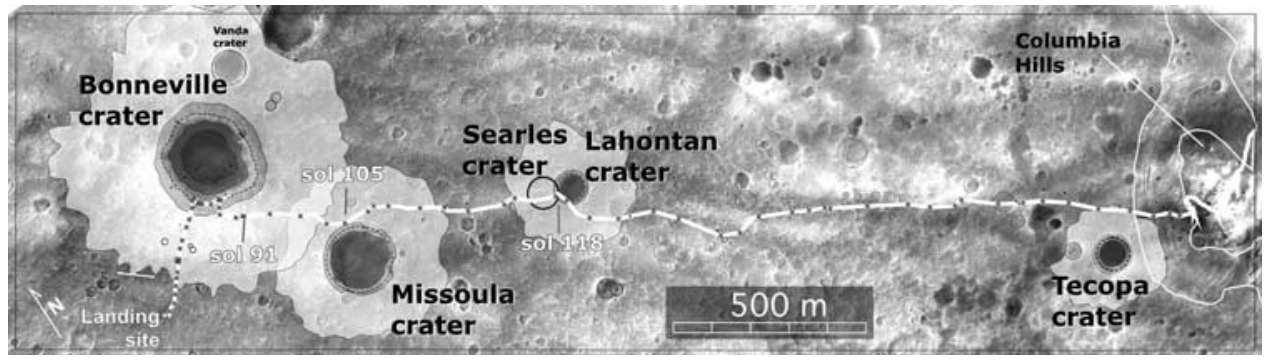

Figure 4. Map of the Spirit rover traverse across the Gusev plains showing the location of large craters and their ejecta deposits and overlain on Mars Orbiter Camera (MOC) imagery. Traverse extends from the Columbia Memorial Station landing site to the rim of Bonneville crater and then past Missoula, Searles, Lahontan, and, finally, Tecopa craters before reaching the base of the Columbia Hills.

near the rim, the durability of surface lags, and piracy of the headwater rim area by the steeper interior drainages (which decrease the exterior stream power and scale). Nevertheless, patchy continuous ejecta persist beyond the near-rim [Grant et al., 1997].

[11] Though not precise, the above sequence reflects the evolving importance of gradational processes at terrestrial craters and highlights the importance of fluvial processes on overall crater form, even where infilling or mantling by drift is important (e.g., Roter Kamm). Next, the craters explored within Gusev and at Meridiani are described, and pristine versus gradational morphologic characteristics are distinguished and assessed in order to constrain their gradational form.

\section{Impact Craters Observed Along Spirit Traverses in Gusev Crater}

[12] Craters dominate relief in the vicinity of the Spirit landing site (Figure 4), ranging in size from less than one to more than $200 \mathrm{~m}$ in diameter [Grant et al., 2004], and their size-frequency distribution (Figure 5) indicates that the surface is Hesperian in age [e.g., Golombek et al., 2003]. Orbital views of the craters from the Mars Global Surveyor Mars Orbiter Camera (MOC) highlight what often appear to be subdued, shallow forms that possess depth-to-diameter ratios generally less than 0.1 (Figure 6) [Hurst et al., 2004]. Views from the surface, however, reveal craters whose expression falls into two broad categories [Golombek et al., 2006]. Larger craters possess meters of relief, whereas craters tens of meters in diameter and smaller are generally more modified and are referred to as "hollows" [Grant et al., 2004; Squyres et al., 2004a]. None of the craters exposes bedrock, but all are surrounded by basaltic rubble [McSween et al., 2004]. The Spirit rover has investigated (to varying degree) four craters $\sim 100 \mathrm{~m}$ in diameter or larger that include Bonneville, Missoula, Lahontan, and Searles craters (Figure 4) [Arvidson et al., 2006]. Tecopa crater, near the Columbia Hills, was not closely approached and only the ejecta were assessed. In addition, the rover has crossed numerous hollows.

[13] Bonneville crater (Figure 7) is characteristic of the larger craters in Gusev, and its dimensions were derived from a Digital Elevation Model (DEM) made using two different stereo image panoramas taken from the southwest and south rim. Distances (over tens of meters) and slopes measured from the DEM were compared with
MOC imagery and are generally accurate to within about a meter and a degree, respectively [Li et al., 2006]. Bonneville is $210 \mathrm{~m}$ in diameter and has a raised rim (Figure 7) that reaches 4.1-6.4 $\mathrm{m}$ above the surrounding plain and lacks pronounced relief along its perimeter that might be associated with rim breaching. The crater averages $10 \mathrm{~m}$ deep with a maximum floor-to-rim-crest relief of $14 \mathrm{~m}$ (Table 1). Interior walls are generally smooth at the 5-10 m scale, are usually concave upward, and lack talus or debris chutes. Crater dimensions and wall slopes average $11^{\circ}$ but range between $6^{\circ}$ and $16^{\circ}$, as measured along 32 evenly spaced lines radial to the crater center. Crater walls are steepest and upwardly convex along the eastern wall of Bonneville, where some of the largest boulders protrude and where several small craters (Table 2) excavated the wall. Eolian drift mantles sections of Bonneville's floor and walls, especially to the south and north. Nevertheless, rocks protrude through the drift

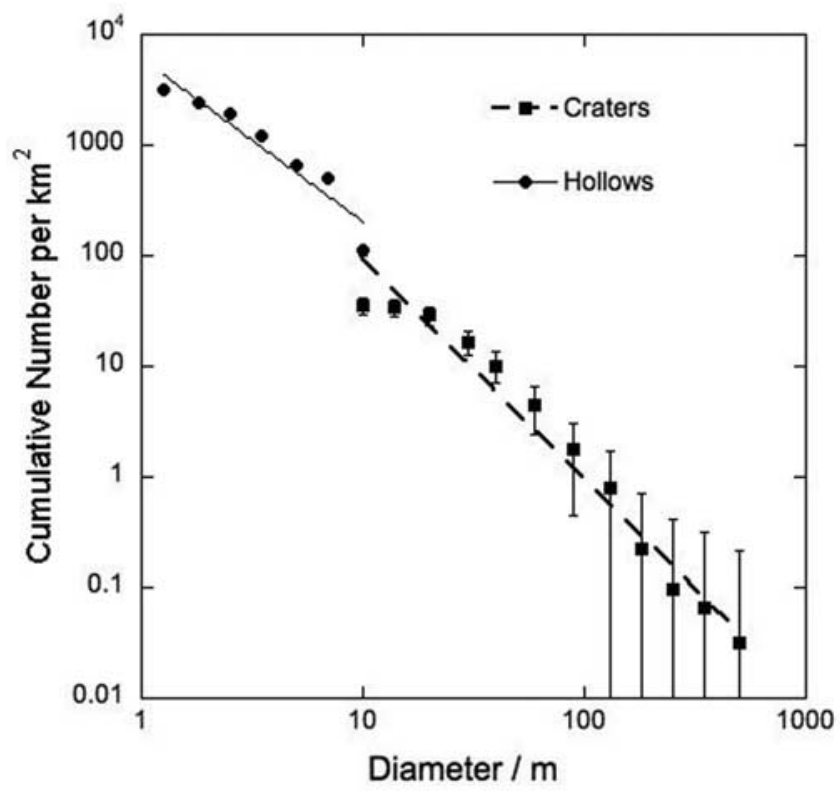

Figure 5. Cumulative total number crater size-frequency distribution of craters, yielding a Hesperian age for the floor of Gusev crater. Statistics include craters counted from orbit, and error bars at the smaller diameters are smaller than the data points on the plot. 


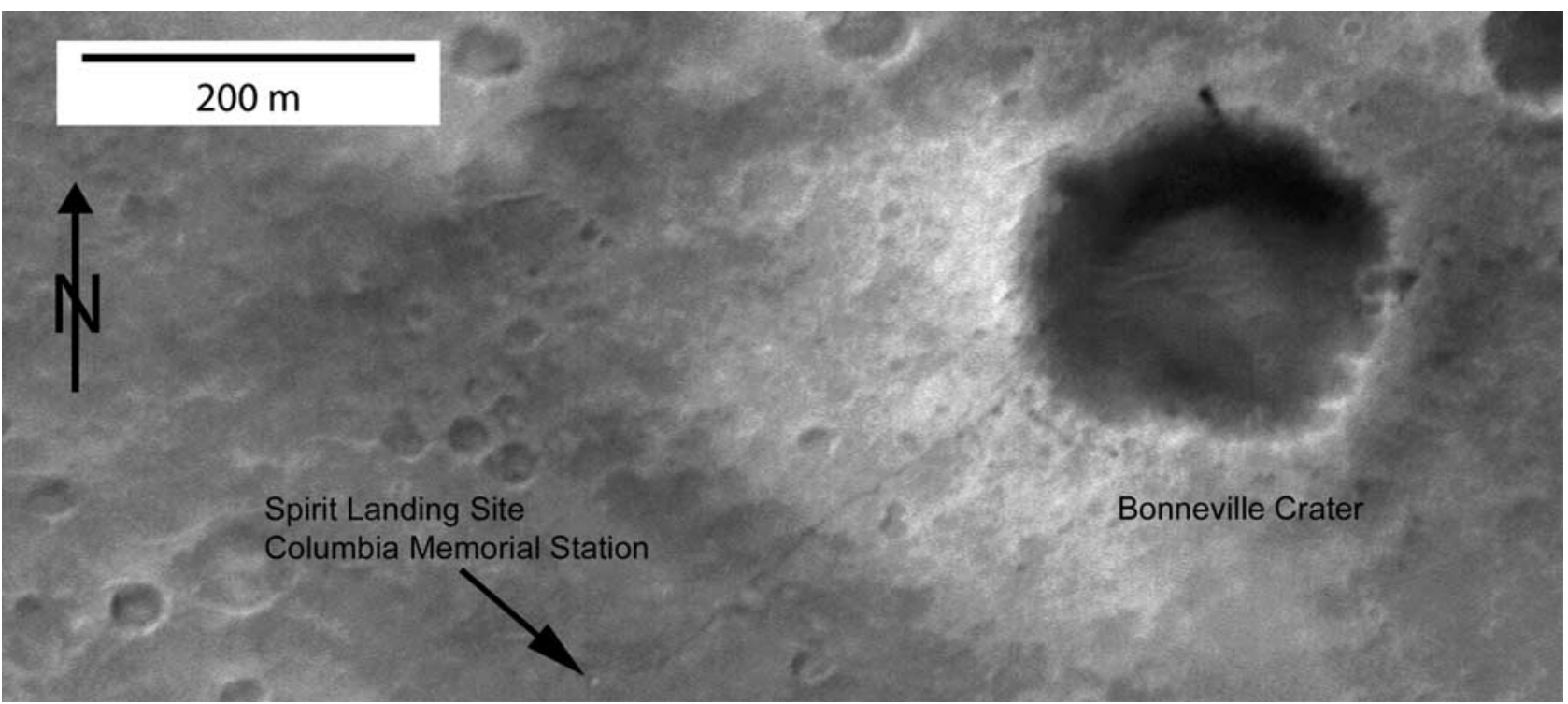

Figure 6. MOC image of the 210-m-diameter crater Bonneville and the area to the west that includes Spirit's landing site. Note the subdued appearance of Bonneville's rim and the smaller hollows. Eolian sediments are visible within Bonneville. The narrow dark line angling from lower left and along the crater rim marks Spirit's traverse over the first $\sim 90$ sols of the mission. The dark spot on the north rim marks the impact of the spacecraft's heat shield. North is toward the top of the MOC c-PROTO image R1502643 of resolution $0.5 \mathrm{~m}$ (north-to-south) and $1.5 \mathrm{~m}$ (east-to-west).

in some locations, and there is no obvious distribution that can be associated with ejecta from a younger impact, thereby suggesting that these rocks are from the floor of Bonneville and that most drift accumulations are only a few meters thick [Grant et al., 2004; Greeley et al., 2004].

[14] Bonneville's ejecta deposit is easily distinguished from surrounding surfaces and displays an abrupt distal margin (Figure 8). A thin mantling of dust causes surface albedo to increase from $\sim 0.19$ on surfaces beyond the ejecta to $\sim 0.26$ nearer the crater rim [Bell et al., 2004]. The largest measured rock fragments within $\sim 10 \mathrm{~m}$ of the rover traverse from beyond the limit of the ejecta up to the crater rim exhibit a fivefold increase in size from $0.5 \mathrm{~m}$ to at least $2.5 \mathrm{~m}$ in diameter at the rim. Partial burial of some of the largest rocks along Bonneville's rim precludes accurate determination of their maximum diameter, but visible fragments confirm an exponential increase in number with decreasing size (Figure 9). When only the smaller rocks $(<10 \mathrm{~cm}$ in diameter) are considered, average sizes also increase toward the crater rim, but by less than a factor of two, from 1.75 to $2.95 \mathrm{~cm}$. These fragments often occur in somewhat regularly spaced clusters (Figure 10) as a result of colluvial processes or redistribution of local fines by the wind which is less effective at redistributing larger fragments [Ward et al., 2005]. Drift is distributed irregularly across the ejecta deposit and rim (Figures 7a and 7b) but is generally only tens of centimeters thick, covered by a veneer of dust, and largely inactive [Grant et al., 2004; Greeley et al., 2004; Golombek et al., 2005a, 2006]. By contrast, lower surfaces of some ejecta blocks are noticeably bright, and a number appear to be ventifacts [Greeley et al., 2004; Golombek et al., 2006] that likely highlight the effects of drift migrating via eolian transport.

[15] Missoula crater is $\sim 270 \mathrm{~m}$ south of Bonneville (Figure 4), and its dimensions were derived from comparison of orbital MOC images and stereo images obtained at a single location along the northeast rim. The crater is $\sim 160 \mathrm{~m}$ in diameter, only $3-4 \mathrm{~m}$ deep, and it retains a raised rim that is $\sim 3 \mathrm{~m}$ in height (Figure 11). Walls slope approximately $6^{\circ}$ in the vicinity of the northeast rim and appear smooth and devoid of talus or debris chutes. Estimates of slope within approximately 40 $\mathrm{m}$ of the imaging location on the rim are accurate to within about a degree, but are less well constrained at greater distances [ $\mathrm{Li}$ et al., 2006]. Nevertheless, images reveal that the walls are fairly uniform in appearance (Figure 11) and that slopes on more distant walls are probably comparable. Relative to Bonneville, Missoula is more completely filled by a mixture of materials: eolian deposits, ejecta from a large hollow on the northeast rim (Figure 11), and some rocks (on the north side of the crater) that may be ejecta from Bonneville.

[16] The size-frequency distribution of the near-rim ejecta fragments at Missoula is similar to the distribution observed at Bonneville (Figure 9), and the largest fragments are just over $1.5 \mathrm{~m}$ in diameter. In general, the edge of Missoula's ejecta deposit can be distinguished from the more distal surrounding plains (Figure 4), and accumulations of superposed eolian drift are comparable in scale and form to those observed at Bonneville.

[17] Other large craters on the Gusev plains were briefly visited and include Lahontan (Figure 12), Searles (Figure 13), and Tecopa (Figure 4) [Arvidson et al., 2006]. Dimensions and slopes were measured employing the same methods used at Missoula. Lahontan has a 


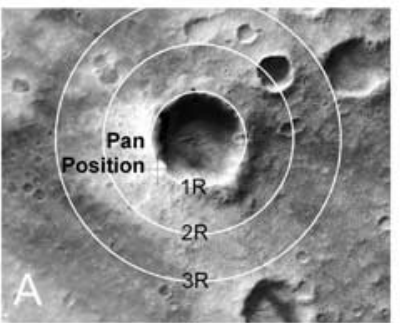

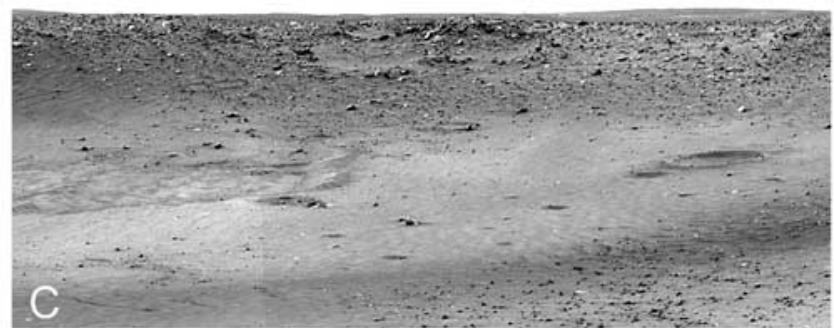

90
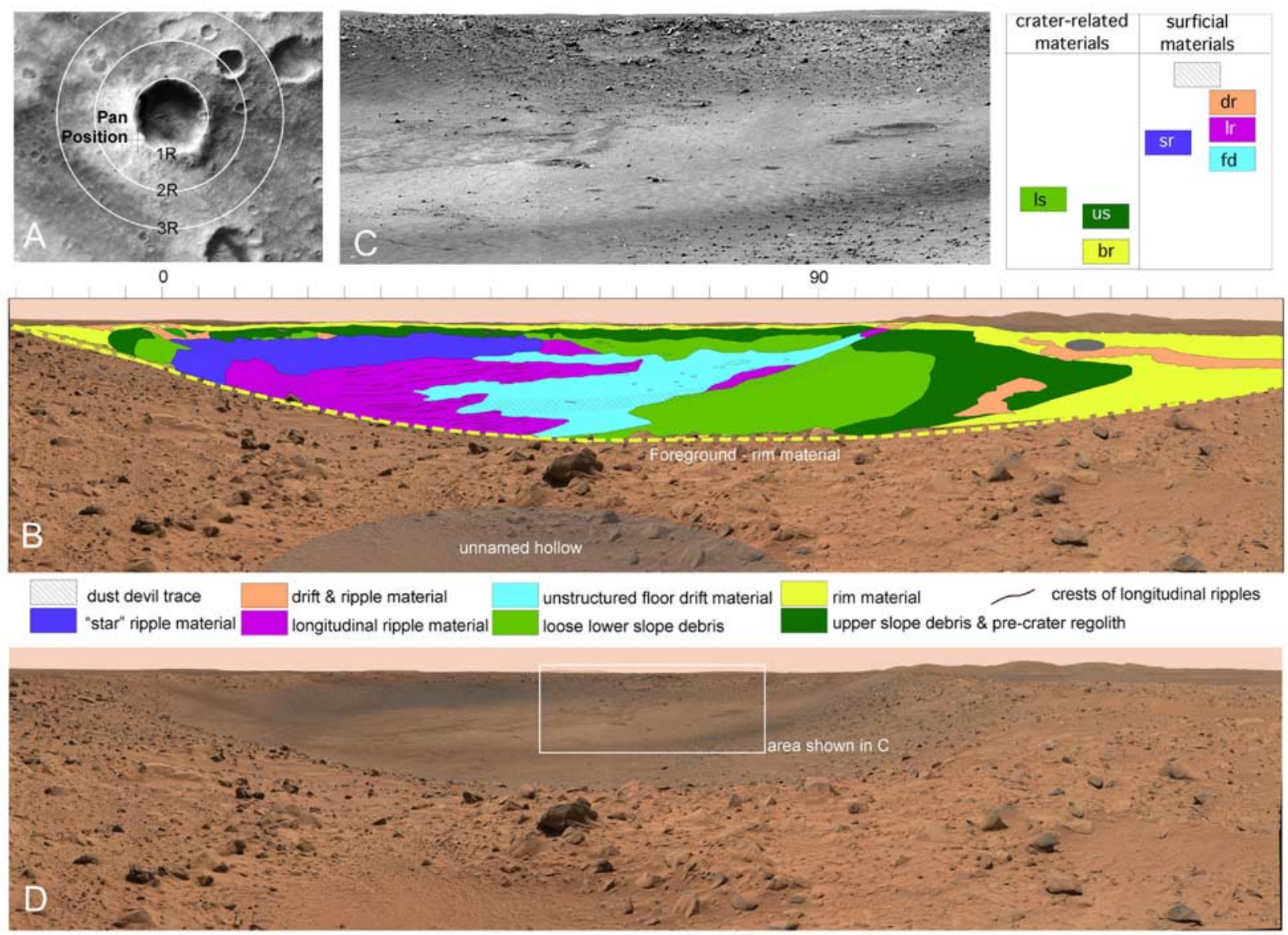

Figure 7. Images of the 210-m-diameter and 10- to 14-m-deep Bonneville crater, showing the blocky nature of the rim, proximal ejecta, eolian sediments that partially mantle the crater floor, and small craters that scar the wall and floor. (a) MOC orbital imagery providing context for rover perspective views in Figures $7 \mathrm{~b}-7 \mathrm{~d}$ and encircled by lines at 1,2 , and 3 crater radii. The position from which the panorama in Figure $7 \mathrm{~b}$ was taken on the southwest rim is indicated. (b) Geomorphic map and image of the crater interior; view is to the north through southeast. (c) View of the crater floor, where a significant number of clasts poke through the crater-filling fines and highlight the relatively thin nature of much of the fill. The clast and block-supported rim materials grade interiorward to sparsely distributed clasts and blocks surrounded by drifted fines. Walls are low sloping and are devoid of obvious talus or debris chutes and are only partially mantled by eolian drift. (c) Small craters excavated into the far wall and floor are a subset of those listed in Table 2, do not expose bedrock, and appear little modified by mass wasting. Figures $7 \mathrm{~b}$ and $7 \mathrm{~d}$ are a portion of the Bonneville panorama color composite acquired on sols 68 and 69 of Spirit's mission. Red is $750 \mathrm{~nm}$, green is $530 \mathrm{~nm}$, and blue is $480 \mathrm{~nm}$. Colors were calibrated to the Pancam calibration target and represent an approximate true color rendering.

diameter of $90 \mathrm{~m}$, a rim height of $\sim 2-3 \mathrm{~m}$, walls sloping at an average of $6-7^{\circ}$, and a depth of up to $4.5 \mathrm{~m}$. Lahontan is also less filled by sediments than Missoula. Searles crater is $\sim 100 \mathrm{~m}$ in diameter, possesses only $1-2 \mathrm{~m}$ of relief, and is mainly filled by deposits that are similar in appearance to those in Missoula. This fill may be a mix of eolian sediments and ejecta blocks. Tecopa is $\sim 100 \mathrm{~m}$ in diameter.

[18] Rim outlines of these three craters are uniform, and their walls are smooth, low sloping, and without talus and debris chutes. Near-rim ejecta sizes at Lahontan and Tecopa are similar to rocks at Bonneville and Missoula (Figure 9), but the near-rim of Searles crater was not closely approached, thereby precluding definition of the largest rock size distribution. Coverage by eolian drift at Lahontan,
Searles, and Tecopa is comparable to Bonneville and Missoula.

[19] "Sleepy Hollow" ( 20 m in diameter (Figure 14)) is immediately adjacent to the Columbia Memorial Station and was one of the first features observed after landing [Squyres et al., 2004a]. The form is typical of larger hollows, although a few display fresh impact crater morphologies (Figure 15). Most hollows are characterized by circular centers with few exposed rocks. Trenching within hollows to depths of $\sim 10 \mathrm{~cm}$ using the rover wheels exposes clast-free accumulations of fines, which are dominated by unaltered basaltic composition but composed of fragments that are too small to be resolved in microscopic images $(<100 \mu \mathrm{m}$ [Herkenhoff et al., 2004a]). Although 
Table 1. Observed and Predicted Pristine Dimensions for Selected Craters in Gusev and Meridiani Planum

\begin{tabular}{|c|c|c|c|c|c|c|c|c|c|}
\hline \multirow[b]{2}{*}{ Site } & \multicolumn{5}{|c|}{ Observed Crater Dimensions } & \multicolumn{4}{|c|}{ Predicted Pristine Crater Dimensions ${ }^{\mathrm{a}}$} \\
\hline & $\begin{array}{c}\text { Diameter, } \\
\mathrm{m}\end{array}$ & $\begin{array}{l}\text { Depth, } \\
\text { m }\end{array}$ & $\begin{array}{l}\text { Rim Height, } \\
\mathrm{m}\end{array}$ & $\begin{array}{c}\text { Ejecta Thickness } \\
\text { at Rim, m }\end{array}$ & $\begin{array}{l}\text { Depth/ } \\
\text { Diameter }\end{array}$ & $\begin{array}{c}\text { Transient } \\
\text { Diameter, }{ }^{\mathrm{b}} \mathrm{m}\end{array}$ & $\begin{array}{l}\text { Transient } \\
\text { Depth, }{ }^{\mathrm{b}} \mathrm{m}\end{array}$ & $\begin{array}{c}\operatorname{Rim} \\
\text { Height, }^{\mathrm{b}} \mathrm{m}\end{array}$ & $\begin{array}{l}\text { Ejecta at } \\
\text { Rim, }{ }^{\text {b }} \text { m }\end{array}$ \\
\hline \multicolumn{10}{|c|}{ Gusev } \\
\hline Bonneville & 210 & $10-14$ & $4.1-6.4$ & N/A & 0.07 & 176 & 65 & 7.4 & 2.3 \\
\hline Missoula & 160 & $3-4$ & $\sim 3$ & N/A & 0.03 & 137 & 51 & 5.7 & 1.9 \\
\hline Lahontan & 90 & 4.5 & $\sim 2-3$ & N/A & 0.05 & 77 & 29 & 3.2 & 1.3 \\
\hline \multicolumn{10}{|c|}{ Meridiani } \\
\hline Eagle & 22 & $2-3$ & $0.1-0.7$ & 0 & 0.13 & 18.5 & 7 & 0.8 & $0.4-0.5$ \\
\hline Endurance & 150 & 21 & $<1-5$ & $0-1^{\mathrm{c}}$ & 0.14 & 126 & 47 & 5.3 & 1.8 \\
\hline Naturaliste & 11 & 2.5 & $<0.5$ & $<0.5$ & 0.22 & 9.2 & 3.4 & $\sim 0.4$ & $\sim 0.3$ \\
\hline Viking & 15 & 3 & $\sim 0.5$ & $<0.5$ & 0.20 & 12.6 & 4.7 & 0.5 & $\sim 0.3$ \\
\hline
\end{tabular}

${ }^{\text {a }}$ Predicted crater dimensions derived using equations (1)-(4).

${ }^{\mathrm{b}}$ May be overestimated if craters are the result of secondary impact events.

${ }^{\mathrm{c}} \mathrm{Almost}$ all ejecta is removed, only very local, nearest rim occurrences where preserved rim is highest.

sediments filling the hollows are covered with a thin veneer of dust, we have not observed discrete dust horizons, unconformities, or accumulations of dust within the fill, thereby suggesting a single episode of geologically rapid infilling. Hollows are typically ringed by rocks, some of which occur in crude, radial concentrations [Grant et al., 2004]. Fractured rocks and rocks exposed on the surface are two to ten times more abundant adjacent to the hollows than out on the plains [Grant et al., 2004]. Despite the exposed position of many rocks around the hollows, there are five to eight times fewer faceted rocks (some of which may be ventifacts [Greeley et al., 2004]) within about $5 \mathrm{~m}$ of the hollows than within comparable proximity to eolian drift.

\section{Crater Gradation Processes Along Spirit Traverses in Gusev Crater}

[20] In general form, craters in Gusev share many common morphologic features that include smooth, low-sloping walls, variably filled interiors, raised rims, and depth-todiameter ratios of less than 0.1 (Table 1). Obvious ejecta deposits with broadly similar rock size-frequency distributions surround the larger craters (Figure 9), and even many of the smaller hollows retain rocky concentrations around their exteriors. Collectively, morphology is consistent with limited gradation since the Hesperian primarily by eolian activity, with lesser impact processes and minimal mass wasting. Comparison to terrestrial craters (Figure 2) reveals no evidence for modification by running water.

[21] Eolian activity fills in craters and causes accumulation of drift around their exteriors. Eolian infilling at Bonneville and Lahontan likely accounts for only a few meters of deposits, based on rocks that protrude or were excavated from beneath the drift by subsequent smaller impacts. Exposed rocks are not distributed to one side of the floor of Bonneville or Lahontan as at Missoula, and there is no young crater nearby that might suggest origin of these rocks as ejecta. More substantial infilling contributes to the shallower form of Missoula, Searles (Figure 4), and most of the hollows (Figure 14). Nevertheless, the limited drift on the walls, rims, and exteriors of the craters, coupled with the easily defined and well preserved nature of their ejecta deposits (Figures 8 and 9), argues strongly against the past occurrence of an extensive, thick mantling deposit or crater infilling followed by exhumation. Observations instead suggest a limited and largely inactive supply of sediment, the bulk of which is trapped within the craters and hollows.

[22] There is good evidence that ongoing formation of small craters contributes to modification of preexisting craters at Gusev. For example, small craters excavated the walls and floor of Bonneville (Figures 7 and 15, Table 2) but failed to expose bedrock. Overlapping ejecta deposits and hollows that superpose Missoula's rims and ejecta (Figure 11) point to additional modification by impact.

[23] Comparison between the craters on the floor of Gusev and terrestrial analogs yields little evidence of mass wasting in these Martian craters. Crater walls are gently sloping and lack any break in slope associated with a transition from erosional wall slopes to depositional debris aprons. There are no debris chutes, talus, or blocks on the margin of crater fill that might record recent mass wasting. Young craters on the walls of Bonneville (Figure 7) create locally steep slopes that are unmodified by mass wasting.

[24] The absence of crater modification by water is demonstrated by smooth crater walls coupled with fairly even rims. None of the incision features associated with appreciable fluvial gradation of terrestrial craters (Figure 2) occurs within or around the craters in Gusev. The expected scale and diagnostic nature of any fluvial forms likely requires that some signature of their action would persist even if gradation by all other processes occurred later. There are no candidate alluvial deposits along crater walls and no evidence for incisement outside of the craters. Although coatings on some rocks exposed by impact indicate the past presence of trace amounts of water [Squyres et al., 2004b], the unaltered nature of most rocks on the plains [McSween et al., 2004] coupled with the absence of fluvial or alluvial

Table 2. Morphometry of Small Craters Superposed on Bonneville

\begin{tabular}{cccc}
\hline Crater Number & Diameter $D, \mathrm{~m}$ & Depth $d, \mathrm{~m}$ & $d / D$ \\
\hline 1 & 10 & 0.5 & 0.05 \\
2 & 7 & 0.5 & 0.07 \\
3.1 & 13 & 0.4 & 0.03 \\
3.2 & 12 & 1.1 & 0.09 \\
3.3 & 12 & 0.6 & 0.05 \\
4 & 5 & 0.4 & 0.08 \\
5.1 & 10 & 0.5 & 0.05 \\
5.2 & 15 & 0.5 & 0.03 \\
5.3 & 15 & 0.5 & 0.03 \\
\hline
\end{tabular}




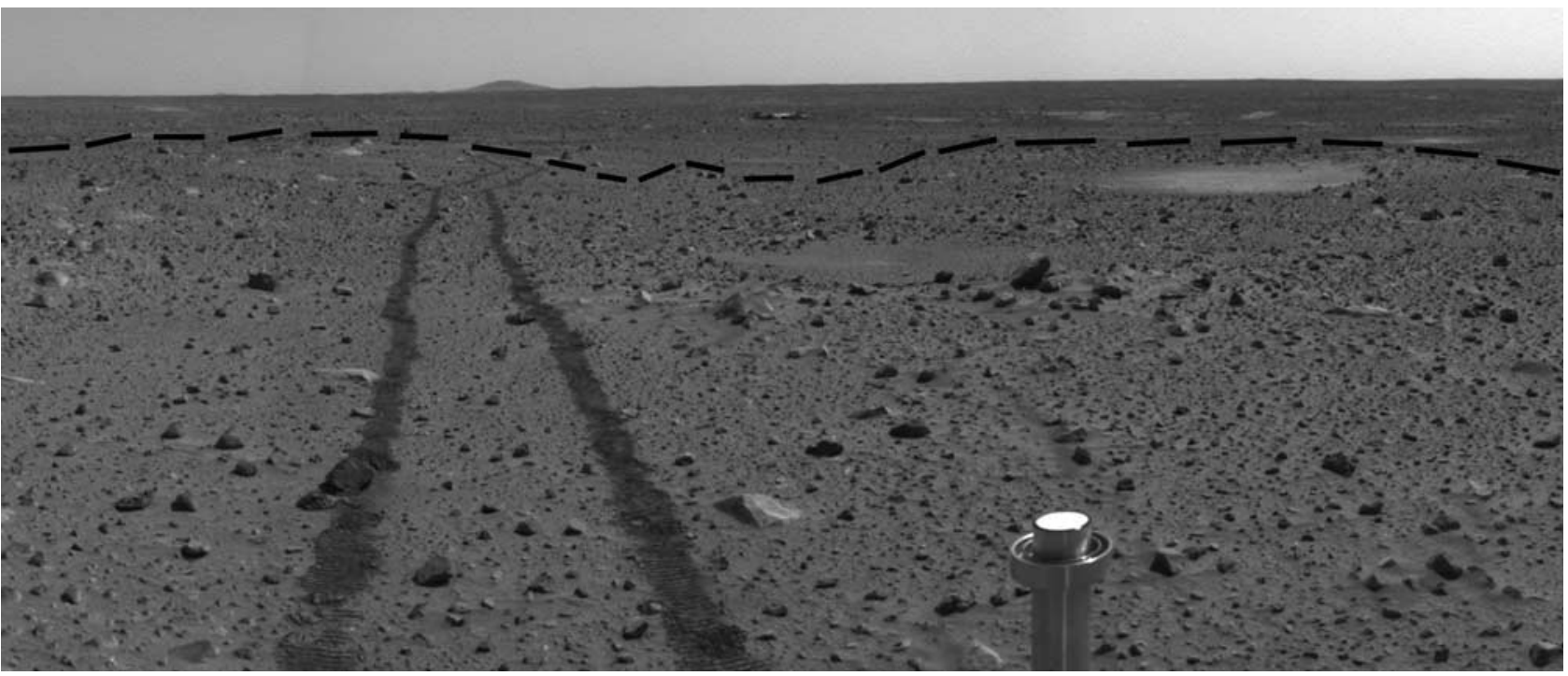

Figure 8. Navcam image showing the sharp distal edge of Bonneville's blocky ejecta deposit and the surrounding plains. View is to the west with Spirit's tracks and lander at Columbia Memorial Station in the distance. Rover tracks are approximately $1 \mathrm{~m}$ apart. Image is a portion of Navcam mosaic 2NN044EFF08CYP00P1817L000M2 obtained on sol 54.

morphology indicates that water inventories (liquid or frozen) were insufficient to produce runoff.

\section{Impact Craters Observed Along Opportunity Traverses in Meridiani Planum}

[25] Although craters explored at Meridiani Planum (Figure 16) are fewer and farther between than at Gusev, their expression dominates the otherwise remarkably lowrelief landscape [Squyres et al., 2004b]. Orbital views from MOC (Figure 16) reveal fairly uniform bright-rimmed craters, some of which may retain ejecta and display faint, relatively high albedo wind streaks extending to the southeast. Surface exploration confirms that some craters possess ejecta but demonstrates a broad range in preservation state that is not apparent or distinguishable in the orbital images. Craters preserving ejecta are sufficiently mantled by eolian drift to preclude determining their associated rock sizefrequency distributions.

[26] All of the craters in Meridiani are formed into sulfate-rich bedrock that originated as reworked dirty evaporites [Squyres et al., 2004b, 2004c], most possess depth-todiameter ratios $>0.10$ [Golombek et al., 2006], and their size-frequency distribution records an Amazonian age [Lane et al., 2003; Golombek et al., 2005a]. Drift within and around the craters is dominated by basaltic grains of unknown provenance, and the drift is often characterized by surface concentrations of hematitic spherules that are generally 2-4 $\mathrm{mm}$ in diameter [Soderblom et al., 2004]. Two of the craters, Eagle and Endurance, have been studied in detail and are emphasized here. More cursory reconnaissance of seven additional impact structures leads to more general descriptions.

[27] The Opportunity rover landed in Eagle crater (Figure 17), and stereo images from multiple locations in and around the crater enabled construction of a detailed DEM that permitted measuring distances and slopes to within tens of $\mathrm{cm}$ and a degree, respectively. The crater is $22 \mathrm{~m}$ in diameter and $2-3 \mathrm{~m}$ deep, and partially sediment filled. It possesses a depth-to-diameter ratio of 0.13 (Table $1)$. The crater rim crest smoothly varies in relief from 0.1 to $0.7 \mathrm{~m}$ (Figure 18), and walls sloping between $10-15^{\circ}$ are highest to the east and lowest to the west side except where local outcroppings persist (Figure 18). Sulfate-rich outcrops are fractured, and eolian erosion creates textured surfaces at the centimeter scale [Herkenhoff et al., 2004b], reflecting the variable degree of induration of the rock. Overall, crater walls are generally smooth at the meter scale, are typically mantled by drift, and are not marked by debris chutes or talus. The crater is clearly infilled by basaltic sands that are especially abundant near the southeast wall [Sullivan et al., 2005]. An absence of protruding rocks precludes determining maximum fill thickness, but trenching with the rover wheel shows a minimum of $\sim 10 \mathrm{~cm}$.

[28] The exterior of Eagle crater lacks ejecta and differs little from the surrounding plains, which consist of a thin (tens of centimeters thick) layer of sediments [Squyres et al., 2004b] swept into low-relief eolian bed forms (Figure 17). The lack of outcrop and abundant sediments outside the crater preclude determining how much ejecta were eroded prior to burial.

[29] Endurance crater is located to the east of Eagle crater. Stereo panoramas from the west and southeast rim and from within the crater enable derivation of a DEM that permits measuring dimensions (over tens of meters) and local wall slopes generally to within a meter and a degree, respectively. Endurance is $150 \mathrm{~m}$ in diameter, and the depth as measured from the rim crest to the lowest point ranges from $17 \mathrm{~m}$ to the west-northwest to $22 \mathrm{~m}$ to the southeast (Table 1). Bedrock exposed continuously around the crater walls reaches from the rim crest to a depth of $>10 \mathrm{~m}$ in some locations (Figure 19). Individual units within the outcrop can be traced along the walls [Grotzinger et al., 2005], which also display offsetting fractures and broadly dipping 


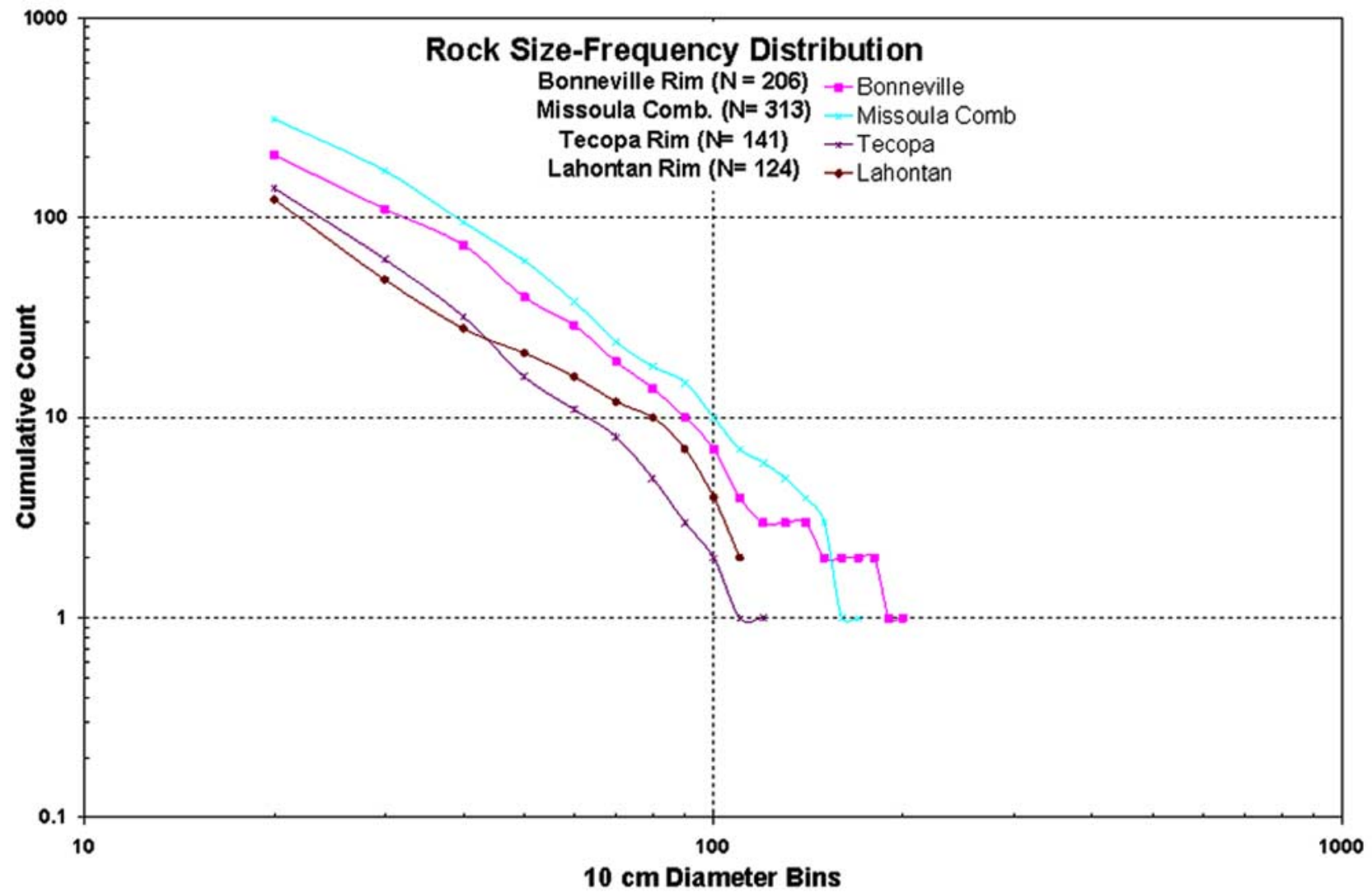

Figure 9. Cumulative distribution of rock sizes (larger than $20 \mathrm{~cm}$ in diameter) in the near-rim ejecta deposits surrounding Bonneville (pink), Missoula (blue), Lahontan (brown), and Tecopa (purple) craters in Gusev. Rocks were counted in $10 \mathrm{~cm}$ bins (not normalized for area) and increase in number with decreasing size in an exponential manner broadly consistent with that expected for pristine craters. The steep slope is due to rock mass being reported as diameter, but cubing values as a proxy for mass lead to slopes ranging between 0.6-0.9, consistent with a multiple fragmentation process [Melosh, 1989]; for Meteor crater ejecta the exponent is 0.8. Largest rocks are smaller than expected if derived from competent bedrock.

structural characteristics that are typical of small, simple craters and extend over distances of tens of meters [Shoemaker and Kieffer, 1974; Grotzinger et al., 2005]. At the meter scale and larger, walls are generally smooth; mostly devoid of rubble, talus, and debris chutes; and wall slopes are generally between $15^{\circ}$ and $30^{\circ}$ (Figure 20) but locally exceed the repose angle. Exceptions occur on the northeast wall, where a promontory reaches up to $20 \mathrm{~m}$ into the crater (Figure 19), and along the upper and middle sections of the wall, where slabs of outcrop and larger boulders occur. At the centimeter scale and smaller, the walls are fractured and variably rough, with more resistant materials (e.g., hematitic spherules and fracture fill) often standing in positive relief [Herkenhoff et al., 2004b]. Some profiles across Endurance display an inflection approximately halfway up the walls that often corresponds to occurrence of large rocks and a transition to locally lower slopes immediately above (Figure 20). Drift composed of basaltic sediments and hematitic spherules [Soderblom et al., 2004] precludes detection of a layer or change in physical properties at this level. This drift mantles the crater floor to an unknown depth, but it contributes to the current depth-to-diameter ratio of 0.14 (Table 1).

[30] As at Eagle crater, rim crest height and distance (as measured from a circular contour on the lower wall of Endurance) correlates with slope, which is lower to the west and higher to the east (Figure 20). Rim relief approaches $5 \mathrm{~m}$ on the southeast corner of the crater, where it is composed of uplifted bedrock and a $\sim 1 \mathrm{~m}$ discontinuous layer of ejecta rubble. Rim relief tapers radially to the level of the surrounding plain over only $40-50 \mathrm{~m}$ distance and is often marked by large plates of disrupted outcrop, which are undercut or have rotated down onto the upper wall of the crater (Figure 19).

[31] No obvious accumulation of ejecta has been recognized beyond the immediate rim, and no other material has been detected that can account for the bright wind streak or ring of varying radial extent around Endurance (Figure 16). Hence the streak may be very thin or the ring surrounding the crater somehow records the past occurrence of ejecta or 


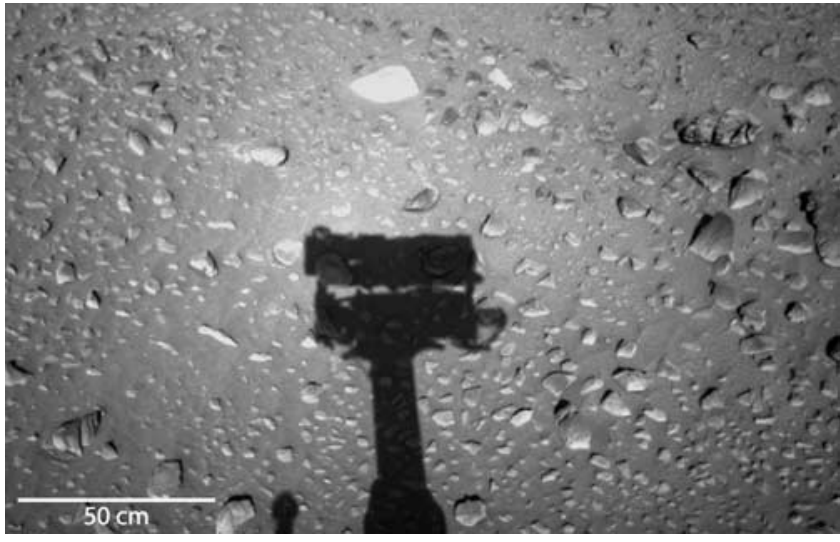

Figure 10. Small clasts $(<10 \mathrm{~cm}$ in diameter) at Gusev often appear sorted and regularly spaced, supporting local redistribution by one or more processes [e.g., Ward et al., 2005], as discussed in the text. Image shows the surface near the rim of Lahontan crater and is a portion of Navcam image 2N136852234FFL639HUPP1950L obtained on sol 118 at site 39 , position 38 . The shadow is of the camera bar on the rover mast assembly, and scale is approximate and for the midfield portion of the oblique view to the south.

results from brighter sulfate-rich rocks and/or is unusually dusty. Surfaces beyond the rim crest are mostly flat (Figure 20) and characterized by closely spaced plates of sulfate-rich rock, often arranged in almost a patio-like fashion.

[32] Seven other craters explored in Meridiani range from $<10$ to nearly $50 \mathrm{~m}$ in diameter and vary widely in preservation state. Dimensions of all of these craters were derived using stereo images obtained from a single near-rim position and are generally accurate to within a meter. The $10 \mathrm{~m}$ diameter and $\sim 1.1 \mathrm{~m}$ deep Fram crater, the $6.5 \mathrm{~m}$ diameter and $\sim 1.4 \mathrm{~m}$ deep Geographe crater, the $11 \mathrm{~m}$ diameter and $\sim 2.5 \mathrm{~m}$ deep Naturaliste crater, and the $15 \mathrm{~m}$ diameter and $\sim 3 \mathrm{~m}$ deep Viking crater (Table 1) are all relatively pristine, and their walls are lined by varying amounts of rubble and drift (Figure 21). Crater depth-todiameter ratios are 0.11 for Fram and close to 0.2 for Geographe, Naturaliste, and Viking, likely owing to more infilling at Fram. Rim relief varies smoothly around the perimeter of the craters, and their walls are devoid of debris chutes and obvious talus. Fram and Naturaliste, however, display a rubble-dominated terrace along their walls that is tens of centimeters below the rim and appears close to the contact between plains drift and bedrock. Hence the terrace could have been created by impact into materials of differing strength (i.e., sand over bedrock [see Quaide and Oberbeck, 1968]). All four of these craters retain ejecta (Figure 21), their exteriors and rims are partially mantled, and some rocks appear planed at the level of the surrounding drift.

[33] The surfaces of exposed rocks are textured at the centimeter scale as a result of differential resistance to erosion. Some rocks (e.g., Pilbara (Figure 22)) display a "barbed" appearance; this form results from the protrusion of more resistant hematitic spherules on protected stalks of sulfate, which stand above surrounding unprotected and more rapidly eroding surfaces [Sullivan et al., 2005]. The texture of the barbs clearly indicates that soft, exposed sulfate-rich rocks on the rims of these craters are undergoing eolian erosion via abrasion by saltating basaltic sand particles.

[34] Several other craters are more degraded, including the $\sim 11 \mathrm{~m}$ diameter Jason and Alvin craters and the $\sim 45-$ $50 \mathrm{~m}$ diameter Vostok (Figure 23). Some outcrop is visible in the wall of Jason, but drift covers most walls, the entire rim, and the exterior; the general form is reminiscent of Eagle crater. By contrast, Alvin crater is completely buried by drift, only a few fragments of sulfate-rich rock may be visible on one wall, and a minimal rim merges almost imperceptibly with the surrounding plains. Vostok has all but disappeared into the plains and is made visible by a narrow ring of light-colored sulfate-rich outcrop that surrounds an only slightly lower interior. Outcrop at Vostok is highly fractured, so it presents a patio-like form similar to that observed outside of Endurance, and the nonexistent rim relief emphasizes the ability of eolian-transported basaltic sands to planate the surface.

\section{Crater Gradation Processes Along Opportunity Traverses in Meridiani Planum}

[35] Comparing gradational morphology at craters in Meridiani with that around terrestrial craters demonstrates the occurrence of widely varying amounts of mostly eolian gradation during the Amazonian. None of the Meridiani craters shows evidence for modification by subsequent impacts, and we observe little evidence for mass wasting and no evidence for gradation by running water.

[36] Eolian processes erode ejecta and transport sediments into crater interiors. On exposed relief, grain impact associated with eolian transport of mostly basaltic grains [Soderblom et al., 2004] strips away the softer sulfate-rich material comprising the bulk of the rock, leaving behind eroded and textured rock surfaces and accumulations that contain more resistant hematitic spherules. A relative paucity of sulfate-rich signatures in the near-surface sediments within and around the craters suggests that rim materials are eroded to sizes that are easily carried away by the wind, possibly contributing to the gossamer wind streak. As a result, sediments around and partially filling the craters are mostly composed of basaltic sands of unknown provenance, whole and fragmented hematitic spherules, and only limited dust [Soderblom et al., 2004].

[37] At Endurance, exposed and eroding outcrop accounts for most of the remaining rim relief. Upper walls are mostly exposed and eroding, but lower walls are more protected and buried by drift (Figure 19). Ejecta persist around Fram and other small craters, but planation of blocks near the level of the encroaching drift demonstrates their vulnerability to eolian erosion (Figure 21).

[38] Expected original ejecta thickness and rim relief at Endurance are derived from equations (4) and (3), respectively, and contrast with the paucity of preserved ejecta (Table 1). Preserved rim relief is typically less than expected for even the structurally uplifted portion of the rim and indicates that erosion of several meters of bedrock is common. In addition, the width of the raised rim is only $40-50 \mathrm{~m}$ (Figure 20 ), much less than the $\sim 90 \mathrm{~m}$ predicted 


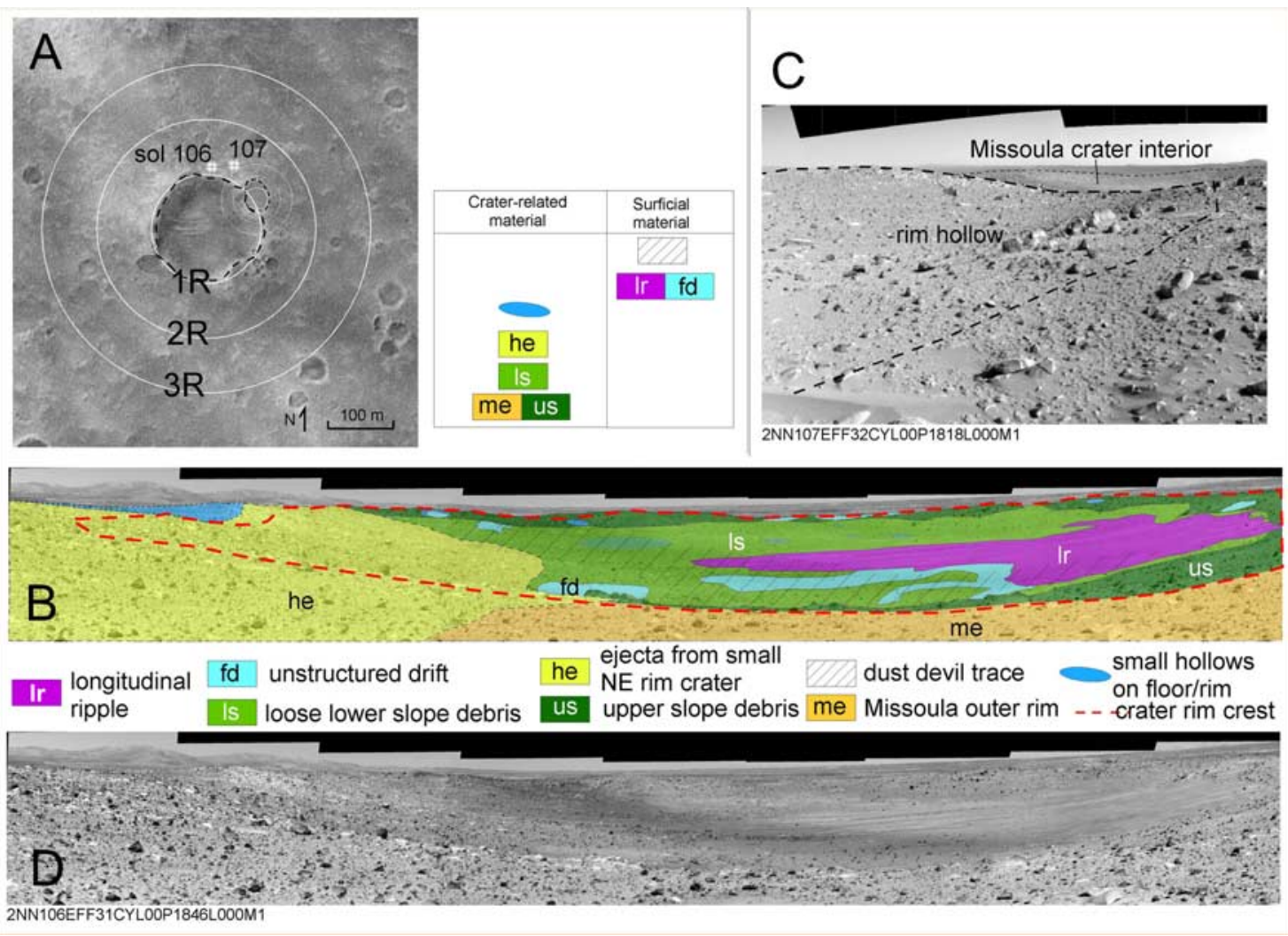

Figure 11. Images of the 160-m-diameter and 3- to 4-m-deep Missoula crater on the Gusev plains. Walls are low sloping, and the crater floor is partially filled by drift and rocks. Much of the ejecta and rim retain a relatively fresh, blocky appearance. (a) Location map using MOC imagery as a base to provide context for rover perspective views in Figures $11 \mathrm{~b}-11 \mathrm{~d}$ and encircled by lines at 1, 2, and 3 crater radii. (b) Geomorphic map of the interior of Missoula crater. In addition to infilling by drifted fines, smaller impact craters on the rim have scattered rim debris across the floor, while reducing the rim height. The concentration of rocks on the northern (foreground) portion of the crater fill is probably ejecta from a hollow on the northeast rim and likely includes Bonneville ejecta as well. (c) View through the notch of Missoula crater rim created by the hollow on the northeast rim. Navcam images used for Figures $11 \mathrm{~b}-$ $11 \mathrm{~d}$ are indicated and were obtained around sol 106.

for a pristine crater of this size [Melosh, 1989]. The rim width likely reflects vertical erosion of exterior surfaces in combination with back wasting of the crater walls.

[39] Clear evidence for back wasting of walls comes from the undercut/overhanging near-rim rocks and the etched appearance of exposed rocks (Figure 19). The limited vertical extent of these rocks along the wall implies rapid breakdown by the wind. The precise amount of wall back wasting is difficult to constrain since the rim form is due to both back wasting and vertical erosion of exposed rim crest and flank surfaces. Nevertheless, the stripped appearance of the upper wall, protrusion of a $20 \mathrm{~m}$ promontory on the northeast wall (Figure 19), and the correlation between increasing radius and decreasing wall slope and rim height around the crater (Figure 20) indicate $\sim 5-10 \mathrm{~m}$ of wall back wasting is realistic.

[40] The current depth-to-diameter ratio for Endurance of 0.14 is slightly higher than expected if the crater was formed as a result of a secondary impact, but lower than the $\sim 0.2$ expected for a fresh primary crater. If Endurance is a primary crater, then an increase in the current depth by about $10 \mathrm{~m}$ or decrease in the current diameter by $\sim 40 \mathrm{~m}$ yields a depth-to-diameter ratio close to 0.2 . Because there is evidence for both crater infilling and back-wasting of the wall, actual values of both back wasting and infilling are probably intermediate and in the range of $\sim 5-10 \mathrm{~m}$.

[41] At Eagle crater (Figures 17-18), lower wall gradients and a subdued form imply significant back wasting and/or infilling, which is consistent with the current depthto-diameter ratio of 0.13 versus the predicted 0.2 (if Eagle is a primary crater). Some wall back wasting is supported by the stripped, mostly rubble-free appearance of the outcrop (as compared to the more pristine Fram and Viking) and the relationship between increasing radius and decreasing wall slope and rim height around the crater. Eagle's current low profile limits additional stripping to local exposures of sulfate-rich outcrop, and deflation is superseded by mantling of most interior and all exterior surfaces by basaltic sediment transported from the surrounding plains. As at Endurance, the paucity of sulfates within the crater fill at Eagle supports the contention that they erodes to a grain size that is easily transported away by the wind. Some combination of up to a $6 \mathrm{~m}$ increase in diameter or up to $2 \mathrm{~m}$ of infilling 


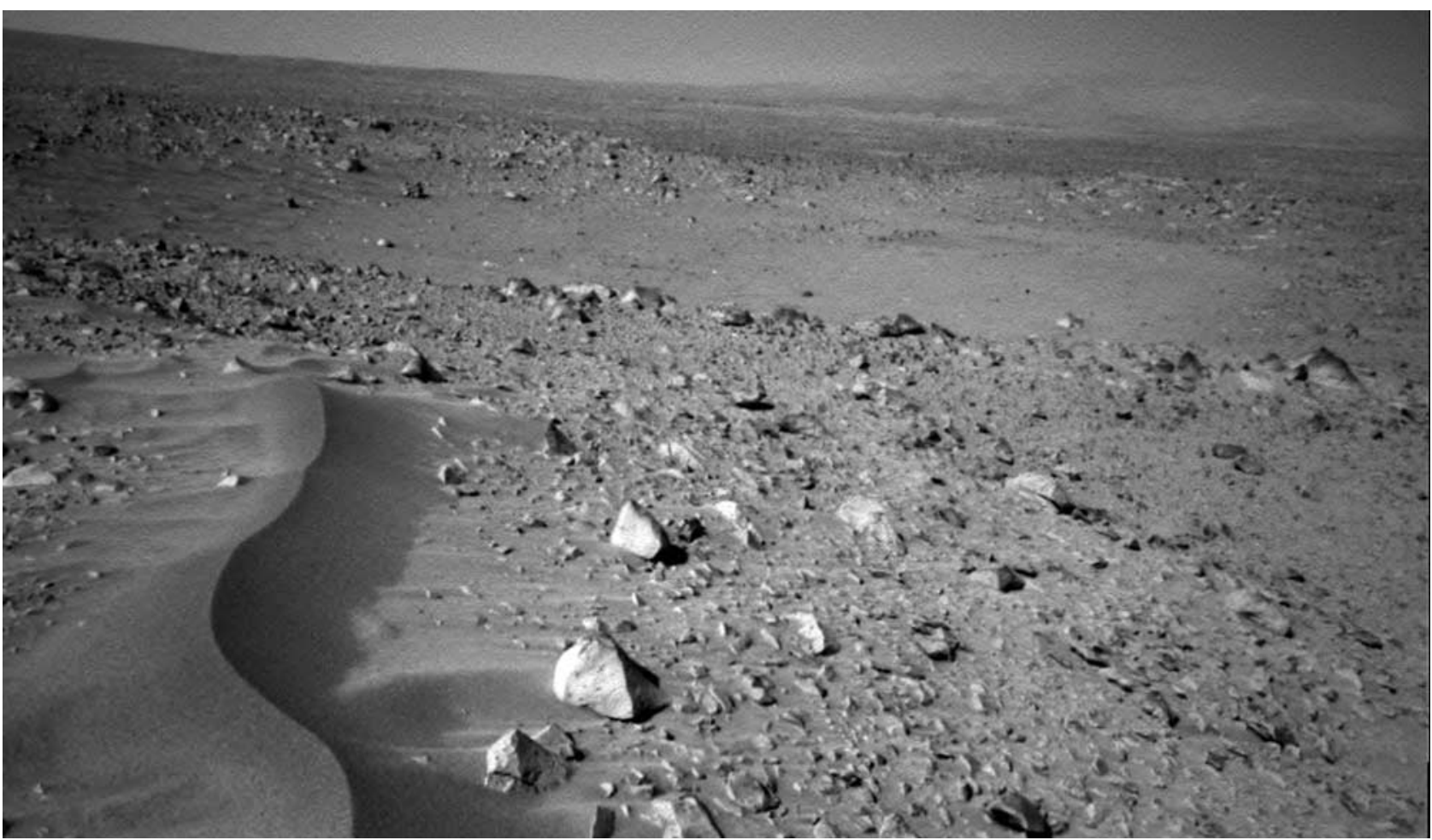

Figure 12. Navcam view of the 90-m-diameter and 4.5-m-deep Lahontan crater. The crater is partially filled with drift, but the rim retains blocky ejecta that are only locally mantled by tens of centimeters of drift. Image 2N137028119FFL4100P1827L taken on sol 120 from site 41, position 0.

is consistent with both the current depth-to-diameter ratio and evidence for infilling and wall back wasting.

[42] Viking, Fram, Geographe, and Naturaliste craters (Figure 21) are distinct from Endurance and Eagle because they preserve varying amounts of ejecta. At Fram, there is no uplifted bedrock exposed along the rim or outer flank, but drift encroaching along the rim partially fills the central floor of the crater. Persistence of angular blocks of sulfaterich rubble along the walls implies minimal back wasting, but the current depth-to-diameter ratio of 0.11 suggests $\sim 1 \mathrm{~m}$ of infilling if the crater is a primary. An absence of rocks protruding from the crater floor drift implies that infilling exceeds $20 \mathrm{~cm}$, resulting in a depth-to-diameter ratio that may approach 0.15 or 0.20 . Nevertheless, the depth of fill is uncertain, and it is possible that Fram is a secondary crater. Naturaliste is the only crater where the rubbly floor remains at least partially exposed and free of drift. Together with the depth-to-diameter ratios of $\sim 0.2$ for

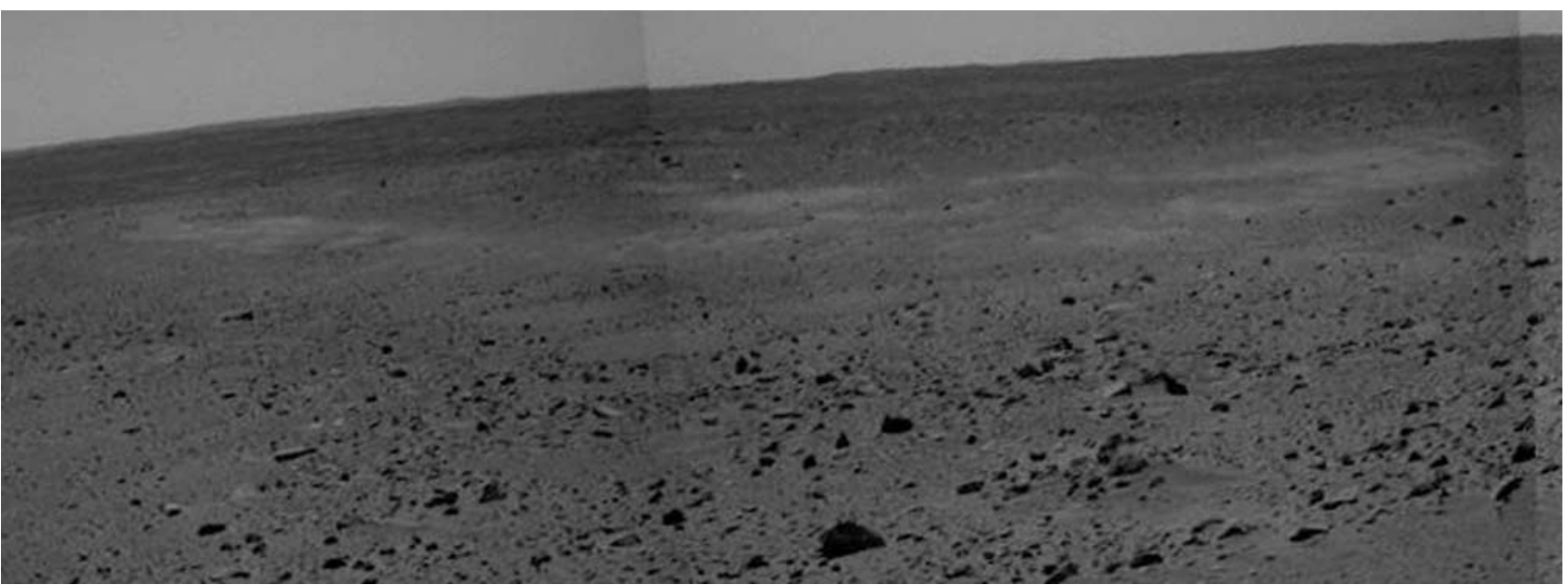

Figure 13. Navcam mosaic of the approximately 100-m-diameter Searles crater. The crater was not closely approached but is more filled with fine drift than is Lahontan. Mosaic comprises images 2N136854180FFL4000P1978L，2N136854004FFL4000P1978L, and 2N136853953FFL4000P1977L collected on sol 118 at site 40 , position 0 . 


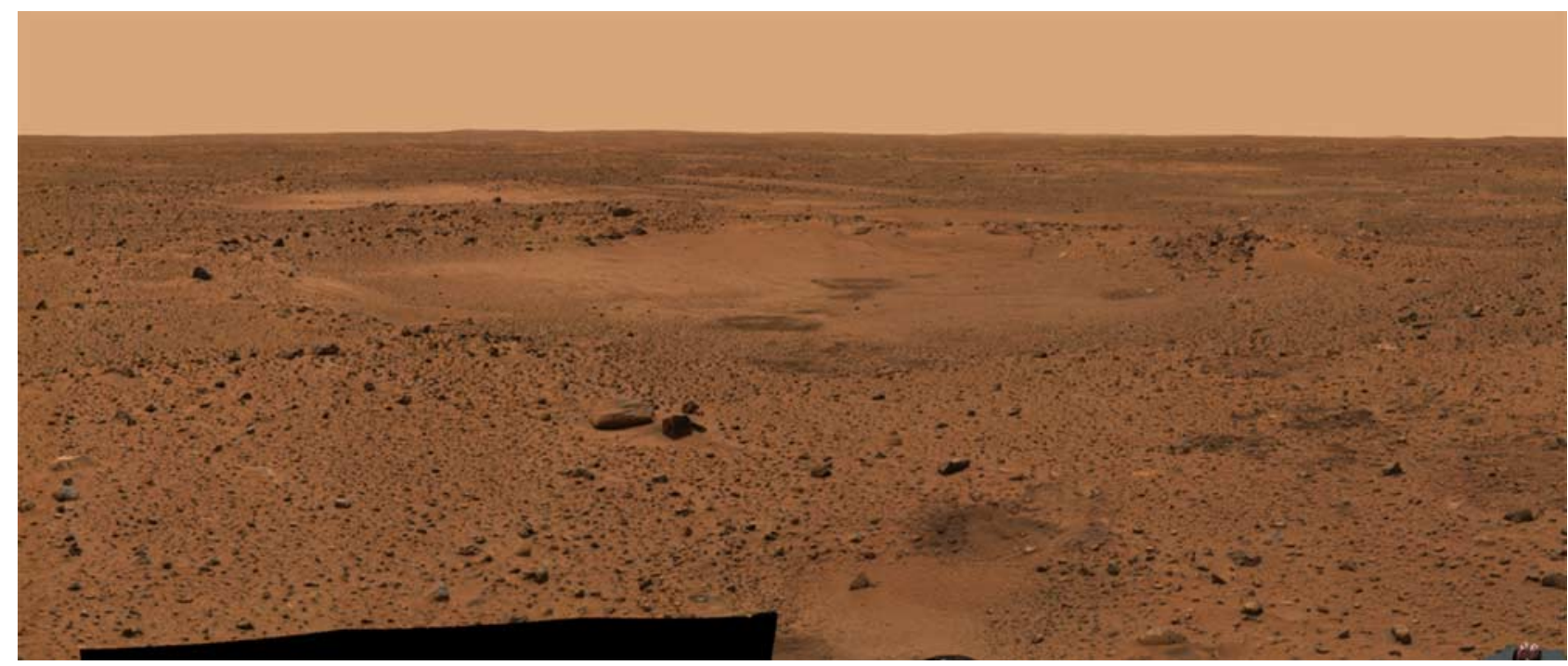

Figure 14. Sleepy Hollow, located approximately $20 \mathrm{~m}$ west of the landing point. The hollow is $\sim 20 \mathrm{~m}$ in diameter and is typical of most hollows that dot the Gusev plains. The view is a portion of the Mission Success Panorama collected on sols 3-5 and is approximate true color based on a color composite using $750 \mathrm{~nm}$ for red, $530 \mathrm{~nm}$ for green, and $480 \mathrm{~nm}$ for blue.

Viking, Naturaliste, and Geographe, the floor morphology implies minimal modification.

[43] Alvin, Jason, and Vostok are the most degraded craters. Their wall slopes are low, rims at Jason and Alvin are completely buried, and Jason and Vostok are almost completely infilled; the present depth of both is only $\sim 1 \mathrm{~m}$. Assuming that Jason and Vostok are primary craters with an original depth-to-diameter ratio of 0.2, analogy with Endurance and Eagle suggests some enlargement may have preceded the significant infilling: infilling may approach $1-2 \mathrm{~m}$ and $6-8 \mathrm{~m}$ at Jason and Vostok, respectively. The ring of fractured outcrop forming the rim at Vostok is likely the eroded core of the structural rim, and planation of the original rim to the level of the current surface would suggest exposed stratigraphy is uplifted $1-2 \mathrm{~m}$ from below the level plain.

\section{A Model for Crater Gradation in Gusev}

[44] All of the gradational morphology at craters explored on the Gusev plains fits a simple model that reflects causative processes, local lithologic properties, and pristine crater form. Crater excavation creates a landform that is composed of variably sized rock fragments (Figure 9 [see Melosh, 1989; Grant and Schultz, 1993]) and has rim and ejecta surfaces that are in disequilibrium with the long-term gradational setting. By analogy with the Earth [Grant and Schultz, 1993], eolian processes modify these surfaces, causing deflation of up to tens of centimeters of fines [Greeley et al., 2004], redistribution of some ejecta clasts to form more stable lag deposits [Ward et al., 2005], and exposure of the numerous perched and fractured rocks around the hollows [Grant et al., 2004]. This lag slows ongoing erosion, and some of the transported fines are deposited and trapped within the craters. Following this geologically brief period of activity, however, the paucity of drift around the craters indicates that the process decreases in intensity with time. Trenching within the smaller hollows exposes dust-free stratigraphy that supports this scenario. Initial postimpact eolian activity is likely accompanied by some mass wasting as rubble-mantled crater walls stabilize, but an absence of gradation signatures associated with significant mass wasting (e.g., debris chutes and talus) indicates that the process is short lived and not responsible for appreciable changes in form.

[45] Longer-term gradation is accomplished slowly [Golombek et al., 2006] by the limited supply of sediments that are suitable for eolian transport. Most available sediments are transported across ejecta and trapped within craters. Production of additional sediments for eolian transport depends on the very slow rate at which resistant basaltic ejecta fragments are weathered in a generally dry environment and on later impacts that produce/expose small fragments. Subsequent impacts also contribute to disruption of preexisting crater forms (Figures 7 and 11) and help to impart an episodic nature to the limited gradation that occurs over time. Limited water-related weathering may contribute some fines for eolian transport and some limited colluvial activity, but runoff has not occurred, so water plays a minimal role in crater gradation in Gusev. Instead, most gradation is accomplished by redistribution of tens of centimeters of material from around to within the craters and hollows, resulting in infilling that varies from meters generally to as much as $10 \mathrm{~m}$ locally (e.g., at Missoula). This sediment redistribution is accompanied by minimal crater enlargement and limited rim lowering (e.g., $\sim 1 \mathrm{~m}$ at Bonneville and Lahontan and $2-3 \mathrm{~m}$ at Missoula, see Table 1), but ejecta deposits remain largely intact.

[46] The relatively unmodified character of the larger craters and their associated ejecta in Gusev is inferred from preserved pristine impact and subsequent gradational morphology. There are aspects of the crater morphologies, however, that may appear inconsistent with this conclusion and require additional discussion. For example, a depth-to- 

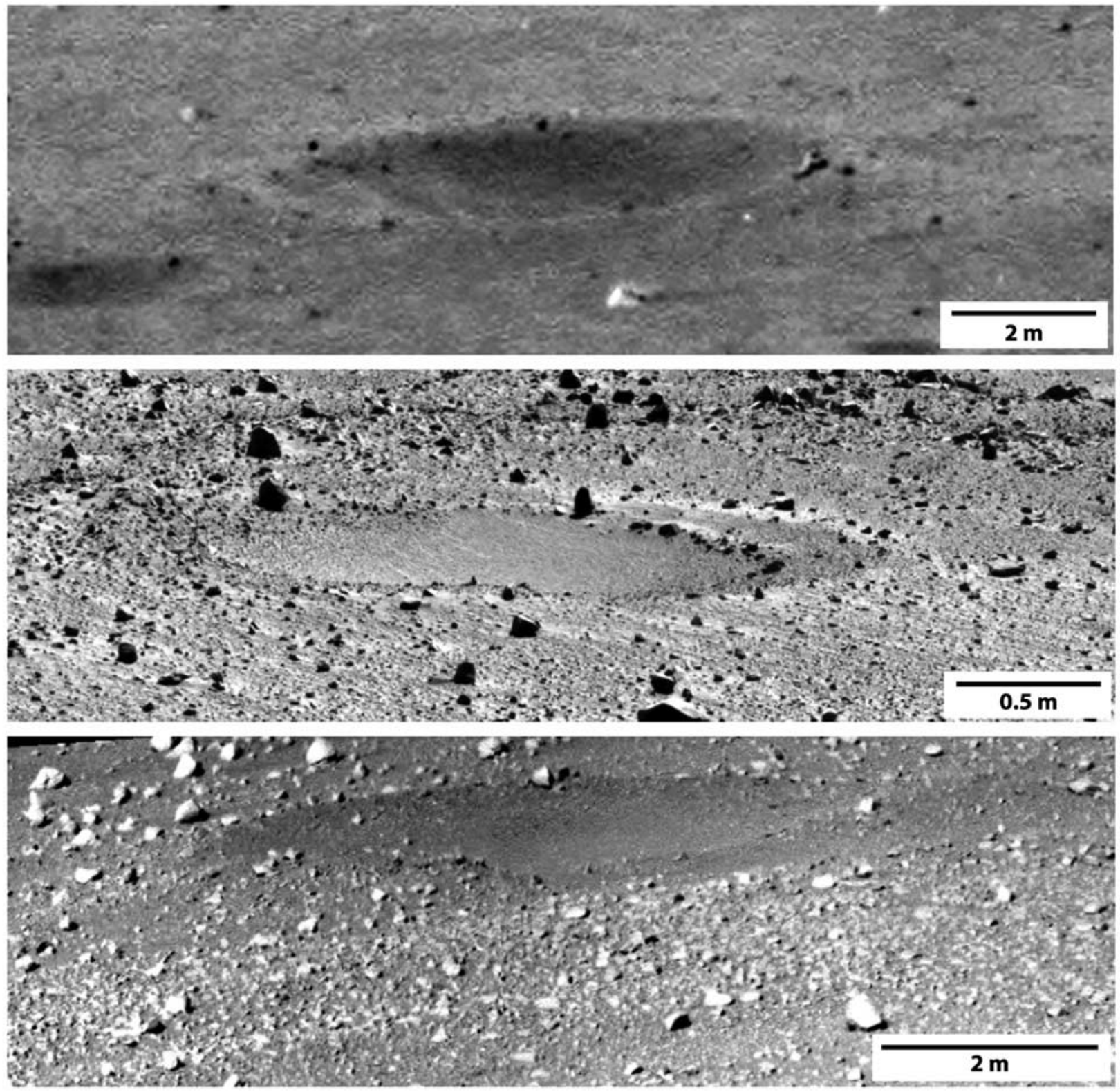

Figure 15. Examples of pristine hollows. (top) An 8-m-diameter crater on the floor of the larger Bonneville crater, unusual in that it contains minimal fill. View is to the east, and the crater was imaged on sol 70 in Pancam frame 2P132587762SFL1800P2836L6. (middle) An 2-m-diameter crater near the base of the east side of the West Spur to Husband Hill. View is to the northwest, and the crater was imaged on sol 324 in Pancam frames 2P155129951FFL9400P2260L7 and 2P155130969FFL9400P2434L7. (bottom) An 6-m-diameter crater imaged near the base of Husband Hill. View is to the southeast, and the crater was imaged in Pancam frames 2P155228395FFL9500P2434L7 and 2P155228545FFL9500P2434L7.

diameter ratio of 0.07 for Bonneville (Table 1) is lower than the 0.2 expected for primary craters [Pike, 1977a; Pike and Wilhelms, 1978]. At face value, the current depth versus diameter might imply that an initial depth of $\sim 40 \mathrm{~m}$ could have been decreased by $\sim 25-30 \mathrm{~m}$ of infilling. Such infilling, however, is inconsistent with the shallow nature of the fill inferred from the distribution of rocks that protrude or were apparently excavated from below the fill by small impacts. Wall gradients averaging only $11^{\circ}$ at
Bonneville are also well below those expected for a pristine primary crater formed into bedrock [Grant, 1999; Grant and Schultz, 1993; Grant et al., 1997].

[47] The absence of exposed bedrock in the walls of Bonneville and Missoula, coupled with the largest measured rock diameters of only 2.5 and $1.5 \mathrm{~m}$, respectively, suggest that the crater was formed by impact into a disrupted basaltic lava plain that is composed of rocks as large as $\sim 6 \mathrm{~m}$ in diameter [Grant et al., 2004]. Overall size 


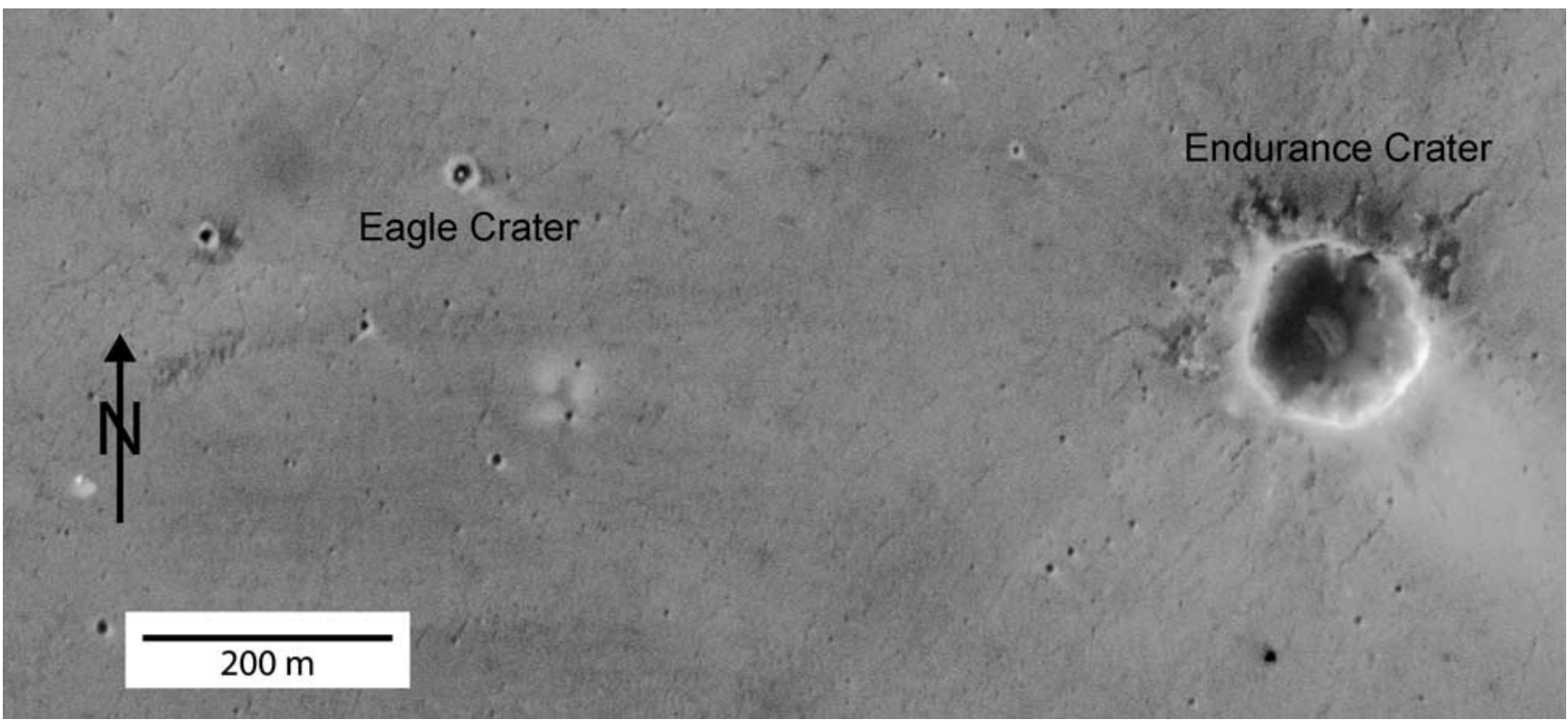

Figure 16. MOC image of the approximately 150-m-diameter and 21-m-deep Endurance crater and surfaces to the west that include the landing site of the Opportunity rover in 22-m-diameter Eagle crater. There are fewer craters than in Gusev, and those present typically possess relatively brighter rims and darker interiors. Endurance is surrounded by a lower-albedo surface of varying radial extent that is most prominent on the north side, and the interior appears to display a break in slope or bench along the southeast side. North is toward the top of the MOC c-PROTO image R1602188 of resolution $0.5 \mathrm{~m}$ (north-to-south) and $1.5 \mathrm{~m}$ (east-to-west). Craters shown in Figures 21 and 23 are located up to $\sim 3 \mathrm{~km}$ to the south of Endurance crater and out of the image.

distributions are consistent with fresh ejecta that has been little modified by weathering (Figure 9), but the largest rocks are smaller than the $3.5-10.5 \mathrm{~m}$ and $2.9-8.6 \mathrm{~m}$ diameters predicted from equation (5) for impact into bedrock. Crater walls may slump to low angles during the final stages of crater formation in such low-strength target materials [Grant et al., 2004].

[48] The low depth-to-diameter ratios and wall gradients for the Gusev craters are more consistent with fairly pristine secondary craters formed into unconsolidated rubble. The expected depth-to-diameter ratio of fresh secondary craters is 0.1 [Pike, 1980; Hurst et al., 2004; McEwen et al., 2005] meaning that Bonneville would require only a few meters of infilling to account for the observed depth-todiameter ratio. Similarly, Lahontan may be infilled by as little as 3-4 m, consistent with the observation of numerous rocks on the crater floor. At the more degraded Missoula, $\sim 10 \mathrm{~m}$ of infilling may account for the current depth-todiameter ratio of only 0.03 , if the crater is a secondary.

[49] Another argument that the craters are secondaries comes from the inspection of small fresh craters superposed on the relatively pristine Bonneville crater (Figure 7). The

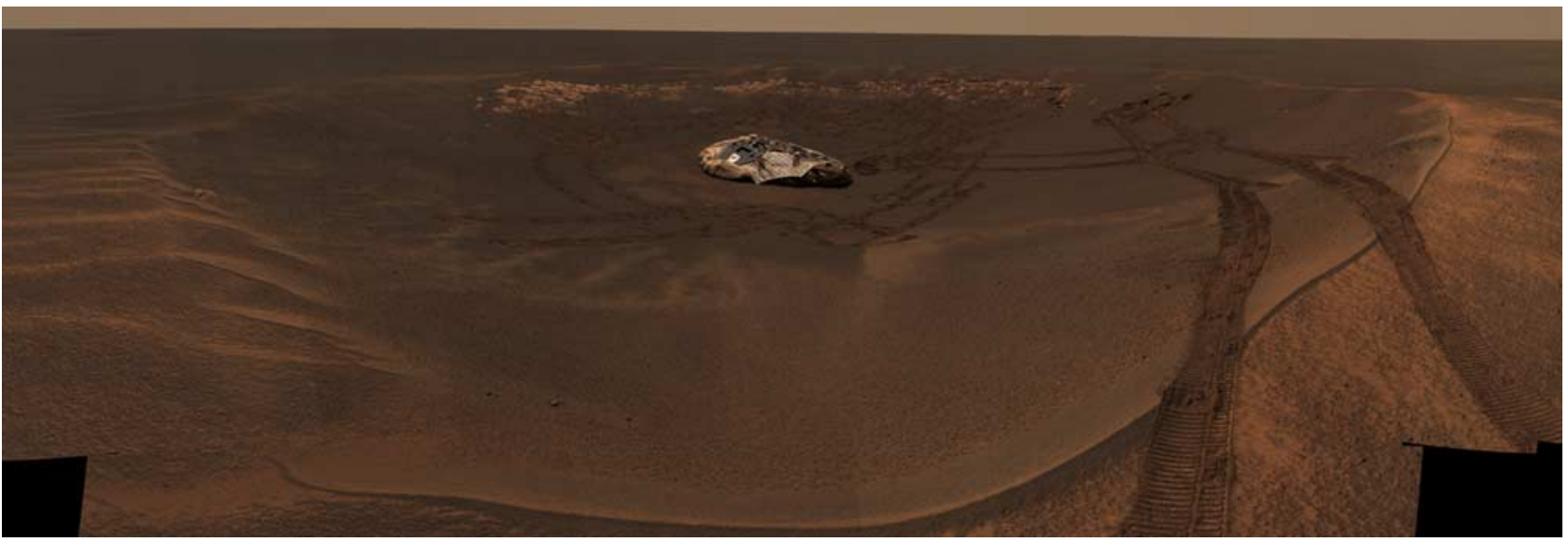

Figure 17. View of 22-m-diameter and 2- to 3-m-deep Eagle crater from the south rim. The lander sits near the center of the crater, and all walls are low gradient and mantled in drift, with the exception of outcropping on the western wall. Portion of the Lion King approximate true color panorama collected on sols 58 and 60 using $750 \mathrm{~nm}$ for red, $530 \mathrm{~nm}$ for green, and $480 \mathrm{~nm}$ for blue. 


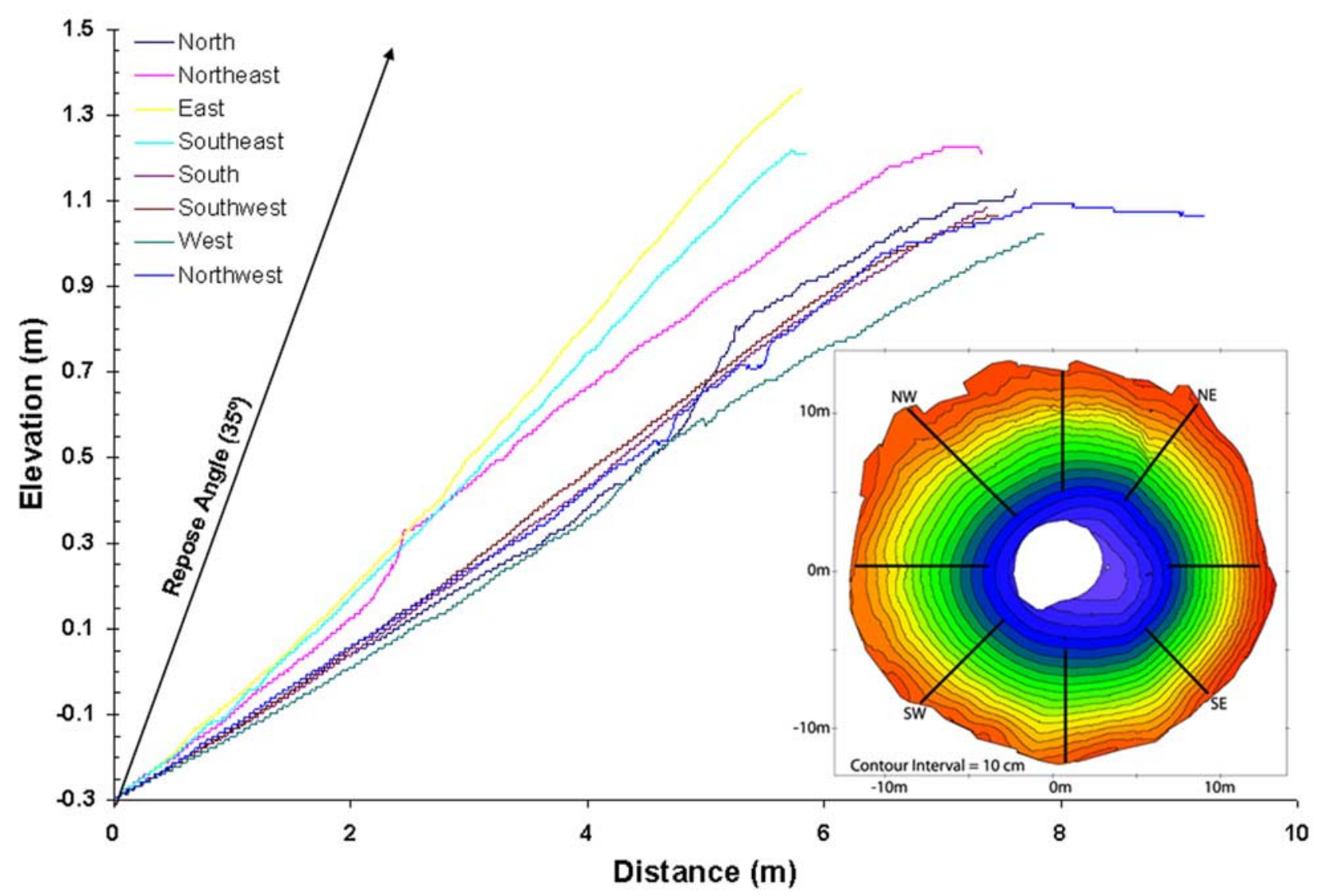

Figure 18. Topography around Eagle crater and profiles along radial transects from a common, circular contour above the level of the bulk of the fill. Wall slopes are correlated with rim height, and both are lowest to the west and highest to the east.

12 small craters $5-20 \mathrm{~m}$ in diameter that formed into the rim and floor of Bonneville occur as three triplets of overlapping craters resembling coeval secondaries. The crater clusters have distinctly noncircular planforms, and although they lie near the limit of reliable stereo measurements, a handful of careful measurements of crater diameter and depth were made (Table 2). All craters are extremely shallow with depth-to-diameter ratios of less than 0.1 , consistent with secondary craters [Pike and Wilhelms, 1978; Hurst et al., 2004; McEwen et al., 2005], and that together with the noncircular planforms and occurrence in clusters support their origin as secondaries.

[50] Larger craters in Gusev appear less modified relative to many of the smaller hollows, because comparable amounts of gradation have greater effects on the overall form of the smaller structures. For example, eolian activity that redistributes tens of centimeters of sediment from outside to within a $10 \mathrm{~m}$ diameter hollow destroys much of the original small-scale impact structure and morphology. By contrast, eolian redistribution of the same amount of sediment around and within Bonneville results in minimal destruction of larger-scale impact signatures (e.g., extent and relief of ejecta, height of the rim). Hence differences in the preservation state of craters are a function of differences in both age and size, and they do not reflect size-selective or grossly varying intensities of gradation over time.

\section{A Model for Crater Gradation in Meridiani Planum}

[51] Eolian processes also account for most of the crater modification observed at Meridiani and are manifested by increasing infilling over time, as forms become more degraded and relief is diminished. Infilling likely predominates at some smaller craters with less initial relief that provides less exposed surfaces for erosion. The combined effects of all other processes are minor in comparison. No superposed craters or associated ejecta deposits were identified that might assist in gradation of older craters, and any early mass wasting that might have occurred was quickly overshadowed by eolian modification.

[52] Several observations indicate that much of the eolian erosion and deposition was related to winds with an eastwest component. First, relief and slopes are lower on the west rims and higher to the southeast. Second, basaltic sands appear to accumulate on the southeast corner of the craters, and wind streaks extend to the southeast. Finally, spherule tails on ripples on the plains are oriented orthog- 


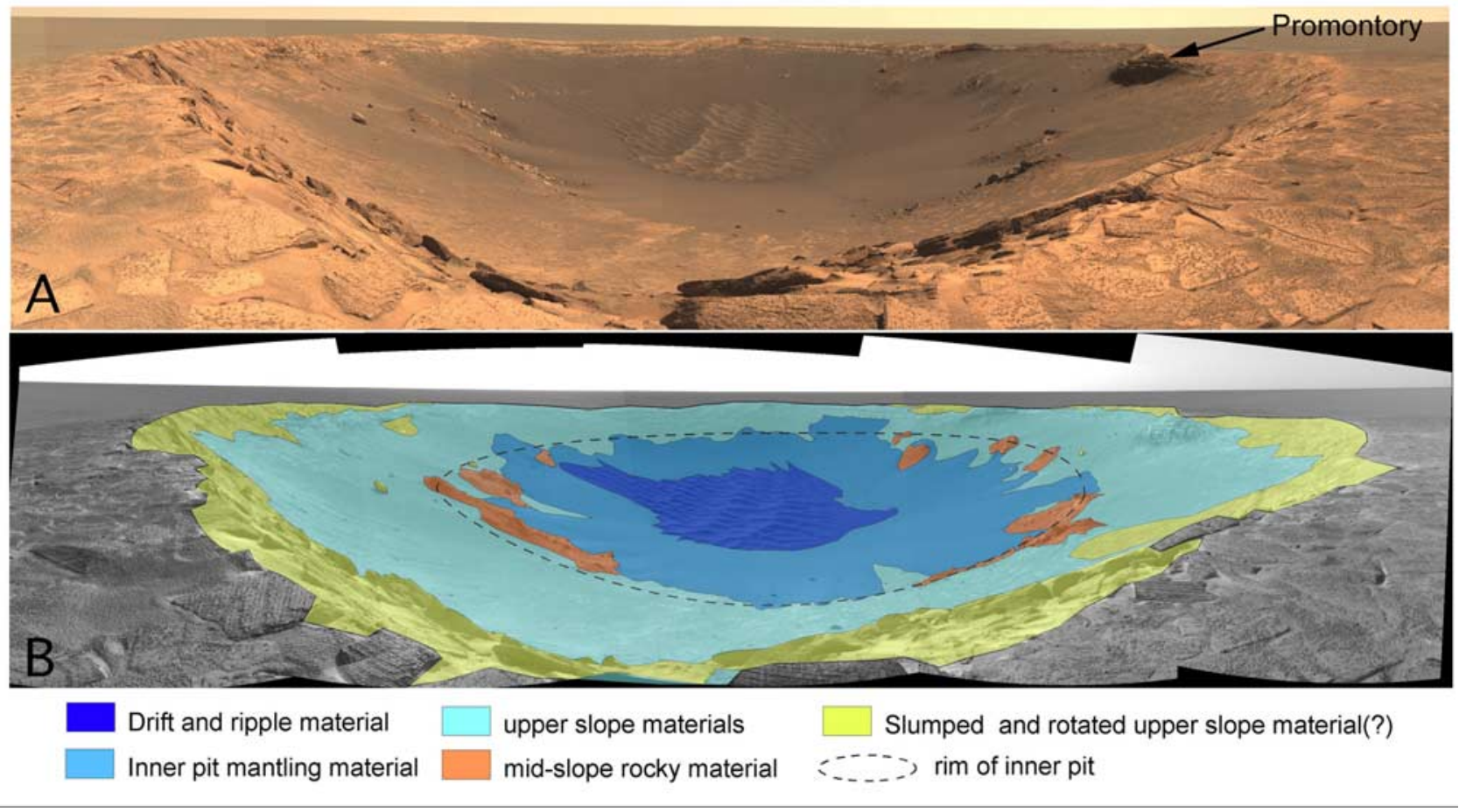

Figure 19. (a) Endurance crater $(150 \mathrm{~m}$ in diameter and $21 \mathrm{~m}$ deep) from the southeast rim and (b) accompanying geomorphic map. Exposed crater walls are stripped/back wasted (light blue), and lower walls and floor are mantled by drift (darker blue). Wall back wasting undercuts rock plates that have rotated into the crater. Rim height and wall slopes are correlated, and the rim plan varies smoothly from highest to the southeast and lowest to the west. A promontory extends $\sim 20 \mathrm{~m}$ into the crater to the northeast at the top right of Figure 19a. The only ejecta are on the southeast wall. No ejecta are detected outside the crater. Portion of approximate true color mosaic from southeast rim of Endurance crater on sols 117-120 using L2, L5, and L6 for red, green, and blue, respectively.

onally to ripple crest lines, which indicates abrasion in an overwhelmingly westward direction [Sullivan et al., 2005].

[53] The generally smooth appearance of crater walls and absence of debris chutes highlights the subordinate role of mass wasting. At more pristine Viking, Fram, Geographe, and Naturaliste craters, rubble-mantled walls show little evidence for downslope movement. Instead, the rocks experience rapid eolian erosion (demonstrated by the "barbed" appearance of some rocks in Figure 22) that strips, back wastes, and stabilizes the walls. There is a single large-scale synclinal feature in the wall of Endurance that may mark the remains of a slump shortly after crater formation (Figure 24), but that feature is more likely structural and created during impact. There is limited talus along upper walls in Endurance, but these rocks enter from above as the wall is back wasted by the wind. The fallen rocks remain exposed and are quickly eroded.

[54] The discontinuous accumulation of large rocks along the lower middle wall of Endurance (Figures 19 and 20) may be the best evidence for past mass wasting in Meridiani. These rocks occur above the crater fill and contribute to an inflection in wall profiles that could relate to impact into a layered target, but it is more likely due to greater back wasting of more exposed walls above.

[55] Differences between the transient and final dimensions of Endurance, estimated from equations (1) and (2), indicate that the transient crater reached a depth of more than $45 \mathrm{~m}$ but was only about $125 \mathrm{~m}$ in diameter (Table 1 ). Hence rocks to depths of $45 \mathrm{~m}$ were excavated during crater formation, but complete removal of ejecta beyond the rim demonstrates that all ejected rocks were of uniformly low strength. Hence if layers are present they possess fairly uniform strength properties and would have had little effect on crater shape.

[56] More likely, late-stage slumping along the walls likely widened the crater, redistributed rubble lower into the cavity [Melosh, 1989], and may have contributed to emplacement of talus along the lower middle wall. Efficient eolian stripping of the upper walls quickly removed loose debris, reduced slopes, and left behind "beheaded" talus remnants on the more protected lower middle walls. If these blocks were delivered by mass wasting, additional support for an erosional origin for the wall inflection relates to the improbable position of the blocks immediately above a transition to locally steeper slopes.

[57] Low-gradient, buried walls at the more degraded Eagle, Jason, Alvin, and especially Vostok craters highlight the minimal role of mass wasting with increasing gradation. Mass wasting may be limited to gravity-driven movement of basaltic sediment that was swept into the craters and moved down their walls to accumulate as fill.

[58] We find no evidence for fluvial modification at any of the Meridiani craters. None of the rims are incised, the walls lack incised debris chutes and rilles, and low-relief 


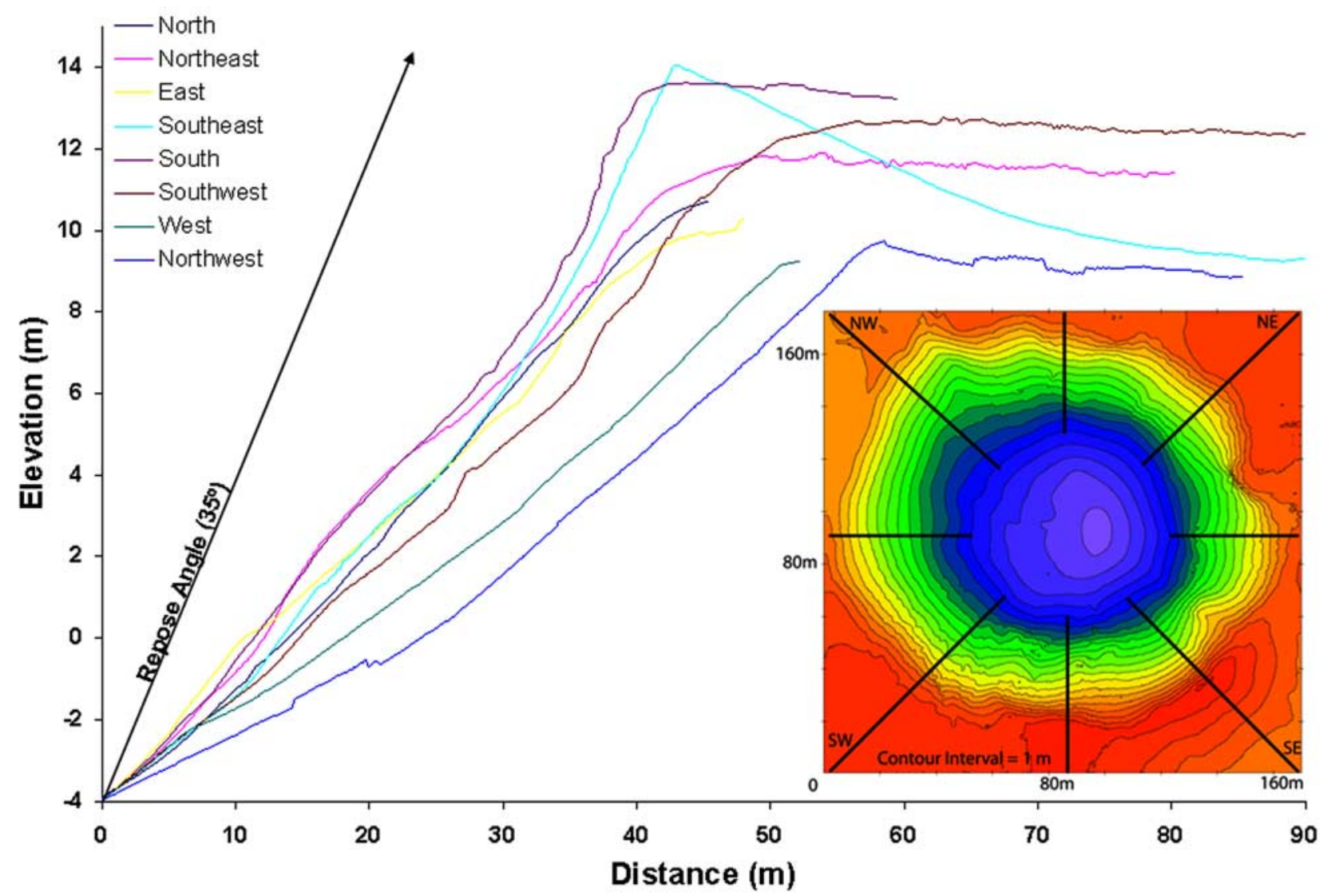

Figure 20. Topography around Endurance crater and profiles along radial transects from a common, circular contour above the level of the bulk of the fill. Wall slopes are correlated with rim height, and both are lowest to the west and highest to the east.

crater exteriors are devoid of any fluvial or alluvial forms. Several large sulfate-rich rocks display possible polygonal fracturing (e.g., Escher in Endurance and rocks exposed at Vostok). These rocks may be related to minor amounts of water [McLennan et al., 2005; Grotzinger et al., 2005] and could have contributed to weathering and alteration of surface textures, but any putative water sources were inadequate to produce runoff. Hence the standing water required for formation of sulfate-rich rocks at Meridiani Planum [Squyres et al., 2004a, 2004b; McLennan et al., 2005; Grotzinger et al., 2005] was gone prior to formation and modification of the craters visited to date.

[59] Craters in Meridiani show a broad range in morphology. This arises mostly from variable duration and amounts of gradation, including eolian stripping of exposed sulfaterich outcrop and infilling that increasingly buries rims, walls, and floors as relief is diminished by erosion and sediments accumulate. This variability contrasts with Gusev, however, where the amount of gradation responsible for overall form is largely dependent on the scale of the crater. The eolian activity at Eagle crater has stripped and/or buried the ejecta, lowered and/or buried rim relief, caused some wall back wasting, up to $2 \mathrm{~m}$ of infilling, and has yielded a fairly degraded form. By contrast, Endurance is better preserved than Eagle, but it has experienced more erosion and infilling. By this logic, Eagle crater is younger but more degraded than Endurance, and other small postEndurance craters are likely to have formed on the plains but have been completely eroded and/or buried. Support for this statement comes from discovery of a $25-30 \mathrm{~cm}$ diameter iron-nickel meteorite at Meridiani that, if it was a primary hypervelocity object impacting locally, could have formed a crater $\sim 10 \mathrm{~m}$ in diameter and close to $3 \mathrm{~m}$ deep (using values from Carr [1981] and Beyer et al. [2000] in equations given by Holsapple and Schmidt [1982] and Melosh [1989]). However, no crater exists near this site, although one may have been completely eroded/buried.

\section{Comparing Crater Gradation in Gusev and Meridiani}

[60] Examination of morphology in and around craters in Gusev crater and at Meridiani Planum allows a comparison of pristine versus gradational characteristics, which record the craters' formation and modification by processes whose relative importance fundamentally differs from those responsible for most crater modification on the Earth. 

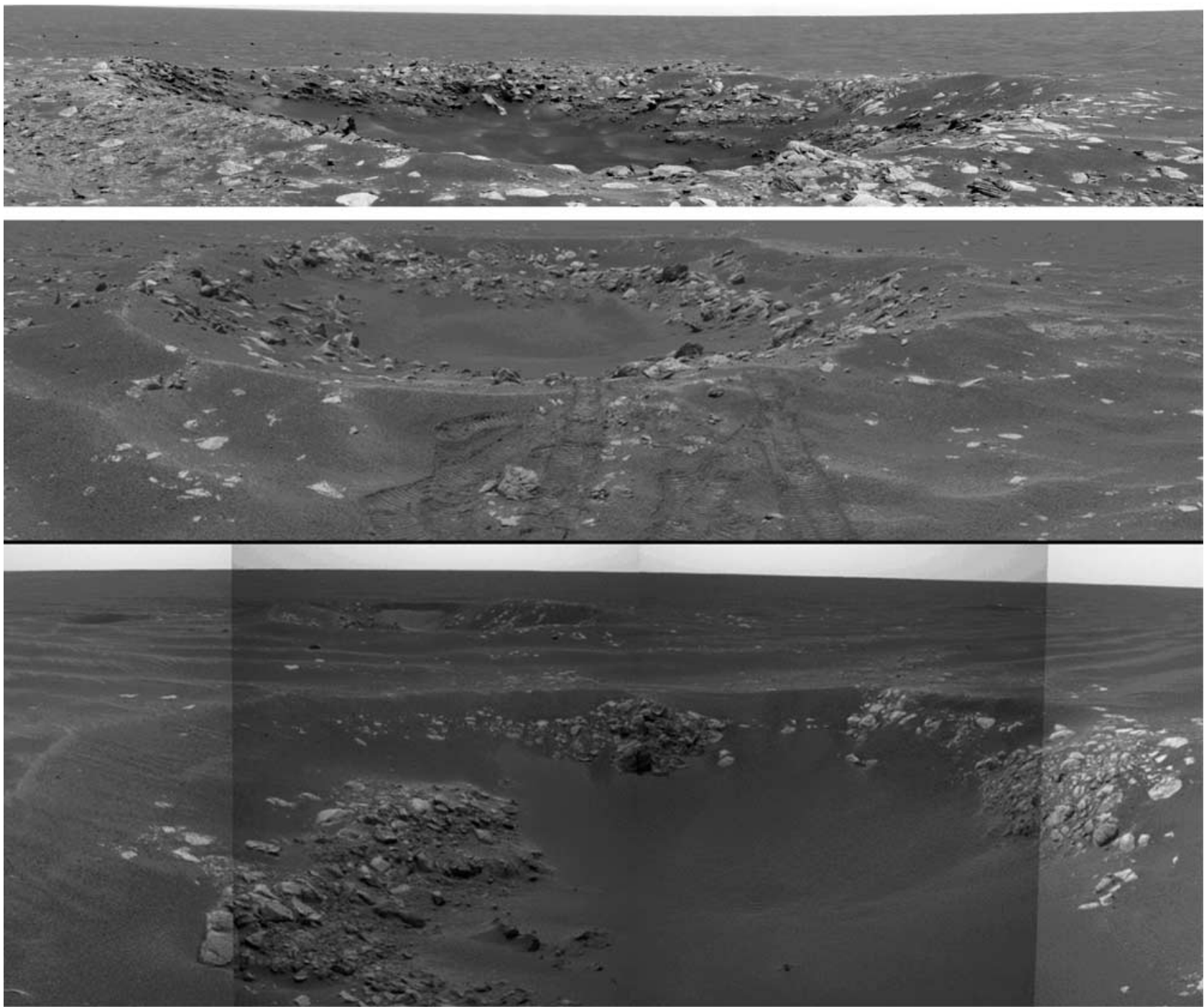

Figure 21. (top) Viking ( $\sim 15 \mathrm{~m}$ in diameter), (middle) Fram (10 $\mathrm{m}$ in diameter), (bottom) Geographe (background, $6.5 \mathrm{~m}$ in diameter), and Naturaliste (foreground, $11 \mathrm{~m}$ in diameter) are the most pristine examples of craters in Meridiani that retain recognizable ejecta deposits and mostly exposed, rubble-lined walls. Viking retains the most ejecta and pristine exterior form, whereas Fram and Naturaliste possess benches on their walls that may be the result of impact into plains sediments that are tens of centimeters thick and underlain by sulfate-rich bedrock. Viking and Fram images are black and white versions of part of color composite mosaics generated using $750 \mathrm{~nm}$ for red, $530 \mathrm{~nm}$ for green, and $430 \mathrm{~nm}$ for blue and acquired on sols 422 and 88 using Pancam sequences P2294 and P2285, respectively, in these views toward the southeast and northeast. West looking Navcam images covering Naturaliste and Geographe (background) were obtained on sol 387 and are 1N162546753FFL4700P0680L and 1N1625467563FFL4700P0680L.

[61] Many of the craters in Gusev appear to be the result of secondary cratering events, but it is not known with which primary crater(s) they may be associated. Observed depth-to-diameter ratios are low, and there is little evidence that they have been significantly modified by gradation. By contrast, most craters in Meridiani appear to be the result of primary cratering events. Current depth-to-diameter ratios range from 0.11 to just over 0.2 , and most show evidence for styles and amounts of gradation that are consistent with modification of pristine, primary craters. Fram remains the sole candidate for a crater formed during a secondary impact event in Meridiani.

[62] Eolian erosion/deposition has been the dominant gradational agent at Gusev and Meridiani since the Hesperian and Amazonian Periods, respectively. Nevertheless, significant differences in the amount and range of modification exist between the two sites. At Gusev, impacts into rubble composed of relatively competent basaltic rocks created pristine craters that are composed mainly of those durable rocks, and only limited sediments were created for transport [Grant et al., 2004]. By contrast, at Meridiani, 


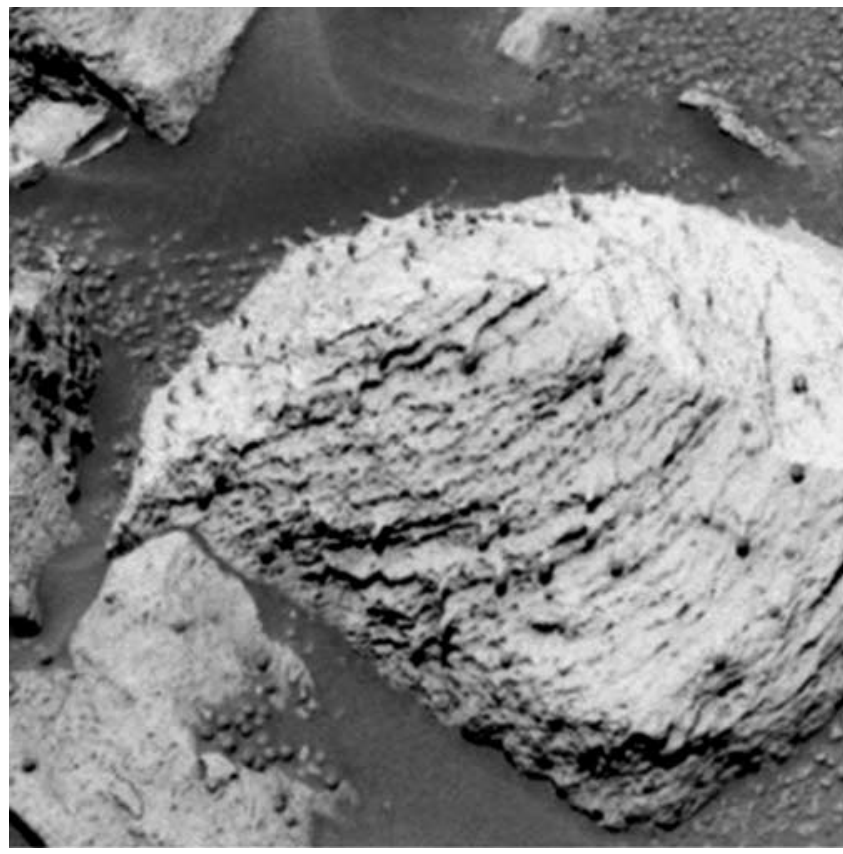

Figure 22. Rock Pilbara on the margin of Fram crater. The rock has evolved a "barbed" texture as the soft, sulfate-rich rock has been stripped away by wind-induced grain impact, leaving more resistant hematitic spherules to protrude on protected stalks. Such rocks highlight the ease with which the sulfate-rich rock is eroded by eolian processes. Image is a black and white version of a false color image generated using Pancam filters L2, L5, and L6 for red, green, and blue, respectively. The image was obtained on sol 85 and is a part of the Pancam sequence P2532.

crater formation into softer sulfate-rich bedrock capped by a thin layer of sediments [Squyres et al., 2004b, 2004c] enables more rapid eolian stripping of relief associated with exposed ejecta, rim, and upper walls, that is accompanied by eolian infilling of the crater interior and eventually the walls and rim. On Earth, fluvial gradation dominates at most craters, with only a few (e.g., Wabar in Saudi Arabia) recording a predominance of the mostly eolian gradational attributes of these Martian craters.

[63] Mass wasting plays a limited role in crater gradation at Gusev and Meridiani relative to Earth, but for different reasons. At Gusev, downslope movement of debris is limited by low-sloping walls that enclose even the most pristine craters. At Meridiani, mass wasting is limited by the high rate of eolian stripping of debris from along the walls that can be back wasted to low angles, further limiting gravity-driven processes. Accumulating fill eventually buries the floor and walls, resulting in further stability. None of these Martian craters possesses attributes associated with significant mass wasting at terrestrial craters.

[64] Impacts have occurred in sufficient number on the older Hesperian surface at Gusev to account for some modification of preexisting craters. The surface retains a fairly complete record of craters smaller than about $0.5 \mathrm{~km}$ in diameter (Figure 5), supporting the contention that the surface has been little modified over time. At Meridiani Planum, the younger Amazonian surface preserves fewer craters, none of which overlap in the area traversed during the first 400 sols of Opportunity's mission. A gap occurs in the preserved crater record between the Noachian, when the sulfate-rich rocks were deposited and conditions were at least occasionally wet, and the present dry conditions [Golombek et al., 2005b]. The ongoing eolian gradation that continues to modify craters at Meridiani may be primarily responsible for this gap in the crater record.

[65] Finally, the absence of evidence for appreciable crater modification by water at both sites highlights the consistently dry conditions since the Hesperian. Analogy with the Earth indicates that some signatures associated with appreciable fluvial gradation should persist (e.g., incised rim) if formed, but such features are not present. Occurrence of small amounts of water at both sites may account for surface coatings at Gusev and polygonal surface textures at Meridiani, but water is not required and did not result in runoff. Instead, craters in these two widely separated locations postdate any earlier wetter conditions [e.g., Squyres et al., 2004b] and record a history of dry conditions that extended over much of later Martian history.

\section{View From Above and Extrapolation to Surfaces Beyond}

[66] Comparing views from the surface and orbit yields additional information regarding gradation in Gusev and Meridiani and to what extent the local gradation may be representative of more regional-scale processes. A review of MOC and Mars Odyssey Thermal Emission Imaging System (THEMIS) images of craters and terrains in Gusev [Golombek et al., 2003; Milam et al., 2003] shows that the surface traversed during Spirit's first 400 sols may be representative of some regional terrain mainly to the north, but it is substantially different from possible mantled and/or etched landscapes to the east. Hence craters examined to date may not be indicative of some of the processes that are responsible for gradation elsewhere in Gusev, and geologic materials may also be variable. For example, mantled surfaces to the southeast may be associated with much larger inventories of fine-grained sediments of unknown origin, whose subsequent transport may lead to more extensive crater infilling. None of the craters on these surfaces, however, appears to record obvious evidence for modification by runoff.

[67] At Meridiani, craters near the landing site may be distinguished from those located farther to the south, but they still may record gradation that is representative of a fairly broad area. The surface traversed during Opportunity's first 400 sols extends well to the east and north of the landing site [Arvidson et al., 2003; Golombek et al., 2003; Hynek, 2004], implying that craters in these areas formed in relatively low-strength rocks that are subject to mostly eolian erosion. It is possible that fundamental differences in crater form (e.g., Erebus crater south of Vostok) reflect differences in gradation processes and/or lithology. Nevertheless, none of the craters located farther to the south preserve evidence for fluvial gradation, and some (e.g., Victoria) display a form that is broadly consistent with the predominantly eolian gradational morphologies evolved at Endurance. 


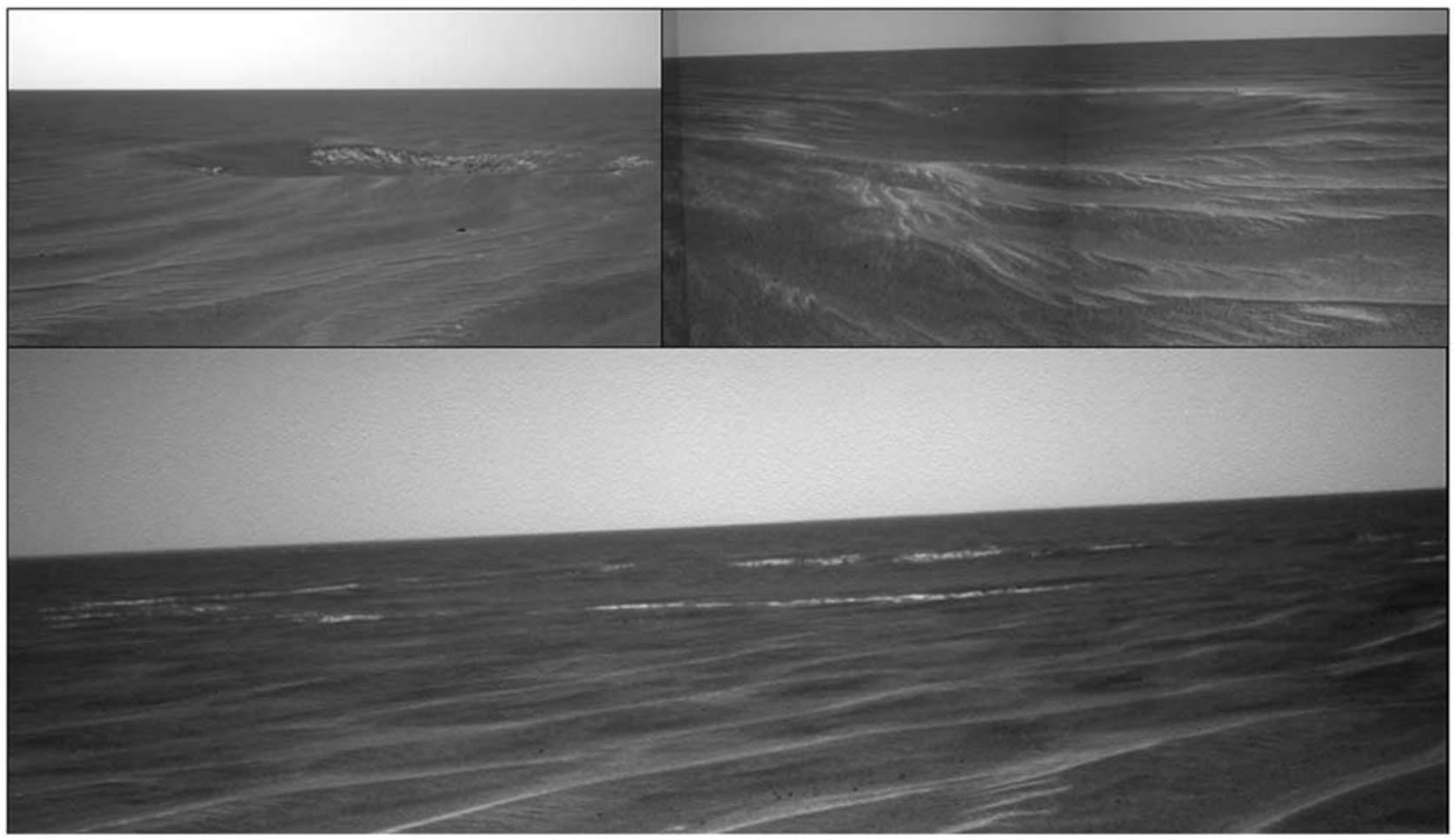

Figure 23. Alvin (11 $\mathrm{m}$ in diameter), Jason (11 $\mathrm{m}$ in diameter), and Vostok (45-50 $\mathrm{m}$ in diameter) craters in Meridiani Planum comprise the most degraded craters visited. Vostok is located approximately $1500 \mathrm{~m}$ south of Endurance crater. Rim relief around all three is subdued to barely detectable, and drift buries all exterior surfaces, most low-gradient walls, and nearly fills the craters. Navcam image of Alvin is 1N162015861FFL4319P1772L, and Navcam frames 1N162098192FFL4336P1617L and 1N162098243FFL4336P1617L cover Jason. Alvin and Jason images were obtained on sols 381 and 382, respectively. Navcam frame 1N163523165FFL4900P0685L from sol 398 covers Vostok.

[68] Finally, the MOC orbital view of the craters studied in both Gusev and Meridiani differs somewhat from the view at the surface. At Gusev, MOC (Figure 6) reveals subdued craters with low depth-to-diameter ratios and without obvious blocky ejecta deposits. Small craters in the southeast wall of Bonneville are poorly resolved and appear as crenulations or spurs. At Meridiani, Endurance crater displays a bench-like feature on the interior wall (especially to the southeast) and appears surrounded (especially to the north and northeast) by a relatively low albedo deposit of differing radial extent (Figure 16). It is also difficult to distinguish pristine craters (e.g., Naturaliste) from more degraded ones (e.g., Eagle) in the orbital data. Such observations could lead to the misimpression that the larger craters visited in Gusev (e.g., Bonneville) are degraded, whereas many in Meridiani (e.g., Endurance) retain extensive ejecta and are more pristine.

[69] Surface exploration at Gusev confirms that the craters are shallow but are partially filled secondary craters rather than degraded primaries. Most of the larger craters are well preserved but formed into rubble, which resulted in lowsloping walls and rocks that are generally too small to be detected from orbit. In Meridiani, the orbital imagery at Endurance emphasizes the break in slope at the transition from eolian stripping to infilling along the talus; this feature is not likely the result of differential excavation in a layered target. Moreover, the almost complete erosion of the ejecta deposit at Endurance is documented on the ground, thereby

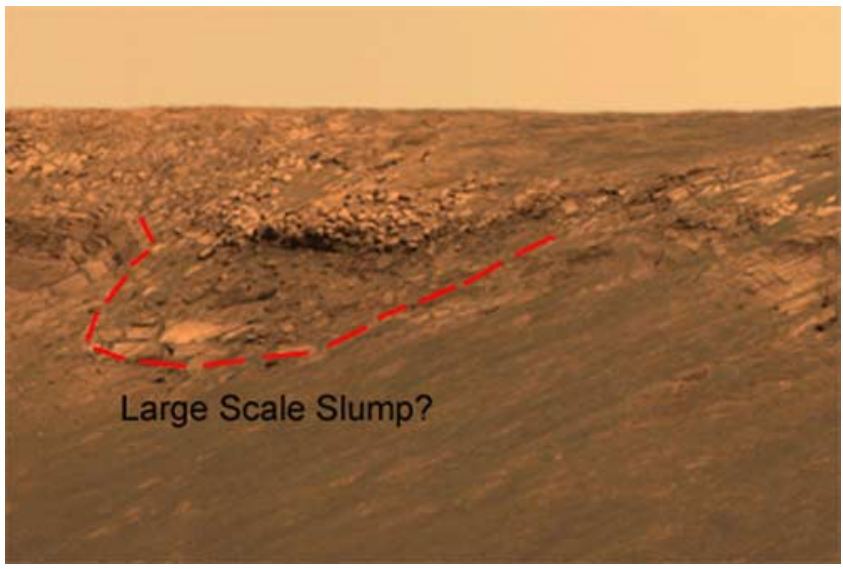

Figure 24. Synclinal structure on the south wall of Endurance crater. Feature may be a large slump that occurred during or just following crater formation but is more likely structural in origin. Image is a portion of an approximate true color mosaic obtained from the western rim of Endurance crater on sols 96-99 using L2, L5, and L6 for red, green, and blue, respectively. 
requiring an alternative explanation for origin of the loweralbedo surface that surrounds the crater as seen from orbit. Given the low strength of the sulfate-rich outcrop, one possible origin for the radial pattern is disruption of the bedrock around the crater during ejecta emplacement, which would be evident today as both any disrupted bedrock and ejecta have been preferentially stripped. These examples from craters in both Gusev and Meridiani demonstrate that higher-resolution and/or surface images may be required for complete and accurate determination of gradation state and processes.

\section{Conclusions}

[70] The Mars Exploration Rovers have examined numerous impact craters in Gusev crater and Meridiani Planum that vary in size and preservation state, are mostly due to secondary impacts at Gusev and primary impacts at Meridiani, and are modified primarily by eolian erosion and infilling. None of the craters displays evidence for modification by running water.

[71] Effects of gradation on crater form are dependent on crater size, local lithology, slopes, and availability of mobile sediments. At Gusev, impacts into basaltic rubble create shallow craters and ejecta composed of resistant rocks. Early eolian stripping of ejecta quickly becomes weathering-limited as lags develop and most available sediments become trapped within craters. Eolian modification is accompanied by only minor mass wasting. Bonneville and Lahontan craters are the most pristine investigated that exceed $\sim 100 \mathrm{~m}$ diameter, whereas Missoula and Searles craters are relatively more modified. Hollows range from relatively fresh small impact morphologies to circular features that are barely recognizable.

[72] At Meridiani, crater rim relief, exposed walls, and ejecta are stripped by the wind, while lower, more protected crater interiors are increasingly infilled and buried by mostly basaltic sediments and more resistant fragments (e.g., hematite spherules). Eolian processes outpace any early mass wasting and often lead to meters of erosion (locally) and wholesale mantling that likely account for complete removal/burial of some craters. Viking, Fram, Naturaliste, and Geographe are the freshest small craters investigated, whereas Eagle, Jason, Alvin, and Vostok are considerably more modified. The larger Endurance crater has likely experienced greater net gradation than the other craters visited, and this has resulted in a gradational form that is intermediate to the smaller more pristine and more degraded impact structures.

[73] Measurements made from the surface demonstrate that craters $>100 \mathrm{~m}$ in diameter on the Hesperian-aged floor of Gusev are generally more pristine than craters on the younger Amazonian-aged Meridiani plains. By contrast, orbital views of Meridiani do not readily distinguish varying crater gradation state, whereas MOC images of craters in Gusev often suggest subdued forms that may suggest more gradation than has occurred.

[74] Acknowledgments. It is impossible to sufficiently thank the MER project for their expertise in the design and operation of such capable rovers. Corey Fortezzo and Ross Irwin assisted in editing and preparing the figures. Constructive reviews by Nadine Barlow and Jeff Wynn helped to improve the manuscript. The work described herein was supported by the National Aeronautics and Space Administration.

\section{References}

Arvidson, R. E., F. P. Seelos IV, K. S. Deal, W. C. Koeppen, N. O. Snider, J. M. Kieniewicz, B. M. Hynek, M. T. Mellon, and J. B. Garvin (2003), Mantled and exhumed terrains in Terra Meridiani, Mars, J. Geophys. Res., 108(E12), 8073, doi:10.1029/2002JE001982.

Arvidson, R. E., et al. (2006), Overview of the Spirit Mars Exploration Rover Mission to Gusev crater: Landing site to Backstay Rock in the Columbia Hills, J. Geophys. Res., 111, E02S01, doi:10.1029/ 2005JE002499.

Barlow, N. G. (2005), A review of Martian impact crater ejecta structures and their implications for target properties, Geol. Soc. Am. Spec. Pap., $384,433-442$.

Bell, J. F., III, et al. (2004), Pancam multispectral imaging results from the Spirit rover at Gusev crater, Science, 305, 800-806.

Beyer, R. A., H. J. Melosh, A. S. McEwen, and R. D. Lorenz (2000), Salt diapirs in Candor Chasma, Mars?, Proc. Lunar Planet. Sci. Conf. 31st, 2022.

Carr, M. H. (1981), The Surface of Mars, 232 pp., Yale Univ. Press, New Haven, Conn.

Garvin, J. B., S. E. H. Sakimoto, J. J. Frawley, and C. Schnetzler (2000), North polar region craterforms on Mars: Geometric characteristics from the Mars Orbiter Laser Altimeter, Icarus, 144, 329-352.

Garvin, J. B., S. E. H. Sakimoto, and J. J. Frawley (2003), Craters on Mars: Global geometric properties from gridded MOLA topography, paper 3277 presented at the 6 th International Conference on Mars, Lunar Planet. Inst., Pasadena, Calif

Gault, D. E. (1970), Impact cratering, in A Primer in Lunar Geology, edited by R. Greeley and P. H. Schultz, pp. 137-175, NASA Ames, Moffett Field, Calif.

Gault, D. E., W. L. Quaide, and V. R. Oberbeck (1968), Impact cratering mechanisms and structures, in Shock Metamorphism of Natural Materials, edited by B. M. French and N. M. Short, pp. 87-100, Mono Book Corp., Baltimore, Md.

Golombek, M. P., et al. (2003), Selection of the Mars Exploration Rover landing sites, J. Geophys. Res., 108(E12), 8072, doi:10.1029/ 2003JE002074.

Golombek, M. P., et al. (2005a), Assessment of Mars Exploration Rover landing site predictions, Nature, 436, 44-48.

Golombek, M. P., J. A. Grant, L. S. Crumpler, R. Greeley, R. E. Arvidson, and the Athena Science Team (2005b), Climate change from the Mars Exploration Rover landing sites: From wet in the Noachian to dry and desiccating since the Hesperian (expanded abstract), Proc. Lunar Planet. Sci. Conf. 36th, 1539.

Golombek, M. P., et al. (2006), Geology of the Gusev cratered plains from the Spirit rover transverse, J. Geophys. Res., doi:10.1029/2005JE002503, in press.

Grant, J. A. (1999), Evaluating the evolution of process specific degradation signatures around impact craters, Int. J. Impact Eng., 23, 331-340.

Grant, J. A., and P. H. Schultz (1993), Gradation of selected terrestrial and Martian impact craters, J. Geophys. Res., 98, 11,025-11,042.

Grant, J. A., C. Koeberl, W. U. Reimold, P. H. Schultz, and D. Brandt (1997), Degradation history of the Roter Kamm impact crater, Namibia, J. Geophys. Res., 102, 16,327-16,388.

Grant, J. A., et al. (2004), Surficial deposits at Gusev crater along Spirit rover traverses, Science, 305, 807-810.

Greeley, R., et al. (2004), Wind-related processes detected by the Spirit rover at Gusev crater, Mars, Science, 305, 810-821.

Grotzinger, J. P., et al. (2005), Stratigraphy, sedimentology and depositional environment of the Burns Formation, Meridiani Planum, Mars, Earth Planet. Sci. Lett., 240, 11-72.

Herkenhoff, K. E., et al. (2004a), Textures of the soils and rocks at Gusev crater from Spirit's Microscopic Imager, Science, 305, 824-826.

Herkenhoff, K. E., et al. (2004b), Evidence from Opportunity's Microscopic Imager for water on Meridiani Planum, Science, 306, 1727-1730.

Holsapple, K. A., and R. M. Schmidt (1982), On the scaling of crater dimensions: 2. Impact processes, J. Geophys. Res., 87, 1849-1870.

Hurst, M., M. P. Golombek, and R. Kirk (2004), Small crater morphology within Gusev crater and Isidis Planitia: Evidence for widespread secondaries on Mars, Proc. Lunar Planet. Sci. Conf. 35th, 2068.

Hynek, B. M. (2004), Implications for hydrologic processes on Mars from extensive bedrock outcrops throughout Terra Meridiani, Nature, 431, $156-159$.

Lane, M. D., P. R. Christensen, and W. K. Hartmann (2003), Utilization of the THEMIS visible and infrared imaging data for crater population studies of the Meridiani Planum landing site, Geophys. Res. Lett., 30(14), 1770, doi:10.1029/2003GL017183. 
Li, R., et al. (2006), Spirit rover localization and topographic mapping at the landing site of Gusev crater, Mars, J. Geophys. Res., doi:10.1029/ 2005JE002483, in press.

McEwen, A. S., B. S. Preblich, E. P. Turtle, N. A. Artemieva, M. P. Golombek, M. Hurst, R. L. Kirk, D. M. Burr, and P. R. Christensen (2005), The rayed crater Zunil and interpretations of small impact craters on Mars, Icarus, 176, 351-381.

McGetchin, T. R., M. Settle, and J. W. Head (1973), Radial thickness variation in impact crater ejecta: Implications for lunar basin deposits, Earth Planet. Sci. Lett., 20, 226-236.

McLennan, S. M., et al. (2005), Provenance and diagenesis of the evaporite-bearing Burns formation, Meridiani Planum, Mars, Earth Planet. Sci. Lett., 240, 95-121.

McSween, H. Y., et al. (2004), Basaltic rocks analyzed by the Spirit Rover in Gusev crater, Science, 305, 842-845.

Melosh, H. J. (1989), Impact Cratering, 245 pp., Oxford Univ. Press, New York.

Milam, K. A., K. R. Stockstill, J. E. Moersch, H. Y. McSween Jr., L. L. Tornabene, A. Ghosh, M. B. Wyatt, and P. R. Christensen (2003), THEMIS characterization of the MER Gusev crater landing site, J. Geophys. Res., 108(E12), 8078, doi:10.1029/2002JE002023.

Moore, H. J. (1971), Craters produced by missile impact, J. Geophys. Res., $76,5750-5755$

Moore, H. J., C. A. Hodges, and D. H. Scott (1974), Multi-ringed basinsIllustrated by Orientale and associated features, Proc. Lunar Sci. Conf., 5 th, $71-100$

Pike, R. J. (1977a), Size dependence of fresh impact craters on the Moon, in Impact and Explosion Cratering, edited by D. J. Roddy et al., pp. 489-509, Elsevier, New York.

Pike, R. J. (1977b), Apparent depth/apparent diameter relation for lunar craters, in Proceedings of the Eighth Lunar Science Conference, vol. 3, Planetary and Lunar Surfaces, edited by R. B. Merill et al., pp. 3427-3436, Elsevier, New York.

Pike, R. J. (1980), Geometric interpretation of lunar craters, U.S. Geol. Surv. Prof. Pap., 1046C, 77 pp.

Pike, R. J., and D. E. Wilhelms (1978), Secondary-impact craters on the Moon: Topographic form and geologic process, Proc. Lunar Planet. Sci. Conf. 9th, 907-909.

Quaide, W. L., and V. R. Oberbeck (1968), Thickness determination of the lunar surface layer from impact craters, J. Geophys. Res., 73, 52475270 .

Roddy, D. J. (1978), Pre-impact geologic conditions, physical properties, energy calculations, meteorite and initial crater dimensions and orientations of joints, faults, and walls at Meteor crater, Arizona, Proc. Lunar Planet. Sci. Conf. 9th, 3891-3930.
Schultz, P. H. (1992), Atmospheric effects on ejecta emplacement, J. Geophys. Res., 97, 11,623-11,662.

Schultz, P. H., and D. E. Gault (1979), Atmospheric effects on Martian ejecta emplacement, J. Geophys. Res., 84, 7669-7687.

Shoemaker, E. M., and S. E. Kieffer (1974), Guidebook to the geology of Meteor crater, Arizona, Cent. Meteorite Stud. Publ. 17, 66 pp., Ariz. State Univ., Tempe.

Soderblom, L. A., et al. (2004), Soils of Eagle crater and Meridiani Planum at the Opportunity Rover Landing Site, Science, 306, 1723-1726.

Squyres, S. W., et al. (2004a), The Spirit rover's Athena science investigation at Gusev crater, Mars, Science, 305, 794-799.

Squyres, S. W., et al. (2004b), The Opportunity rover's Athena science investigation at Meridiani Planum, Mars, Science, 306, 1698-1703.

Squyres, S. W., et al. (2004c), In situ evidence for an ancient aqueous environment at Meridiani Planum, Mars, Science, 306, 1709-1714.

Sullivan, R., et al. (2005), Aeolian processes at the Mars Exploration Rover Meridiani Planum landing site, Nature, 436, 58-61.

Ward, J. G., R. E. Arvidson, and M. Golombek (2005), The size-frequency and areal distribution of rock clasts at the Spirit landing site, Gusey Crater, Mars, Geophys. Res. Lett., 32, L11203, doi:10.1029/ 2005GL022705.

R. E. Arvidson, Department of Earth and Planetary Sciences, Washington University, St. Louis, MO 63130, USA.

L. S. Crumpler, New Mexico Museum of Natural History and Science, 1801 Mountain Road NW, Albuquerque, NM 87104, USA.

M. P. Golombek and A. F. C. Haldemann, Jet Propulsion Laboratory, California Institute of Technology, Pasadena, CA 91109, USA.

J. A. Grant, Center for Earth and Planetary Studies, National Air and Space Museum, Smithsonian Institution, 6th and Independence SW, Washington, DC 20560-0315, USA. (grantj@si.edu)

B. Hahn, Department of Geosciences, State University of New York, Stony Brook, NY 11790, USA.

R. Li, Department of Civil and Environmental Engineering and Geodetic Science, Ohio State University, Columbus, OH 43210, USA

L. A. Soderblom, U.S. Geological Survey, Flagstaff, AZ 86001, USA.

S. W. Squyres, Department of Astronomy, Space Sciences Building, Cornell University, Ithaca, NY 14853, USA.

W. A. Watters, Department of Earth, Atmospheric, and Planetary Sciences, Massachusetts Institute of Technology, Cambridge, MA 02139, USA.

S. P. Wright, Department of Geological Sciences, Arizona State University, Tempe, AZ 85287, USA. 